
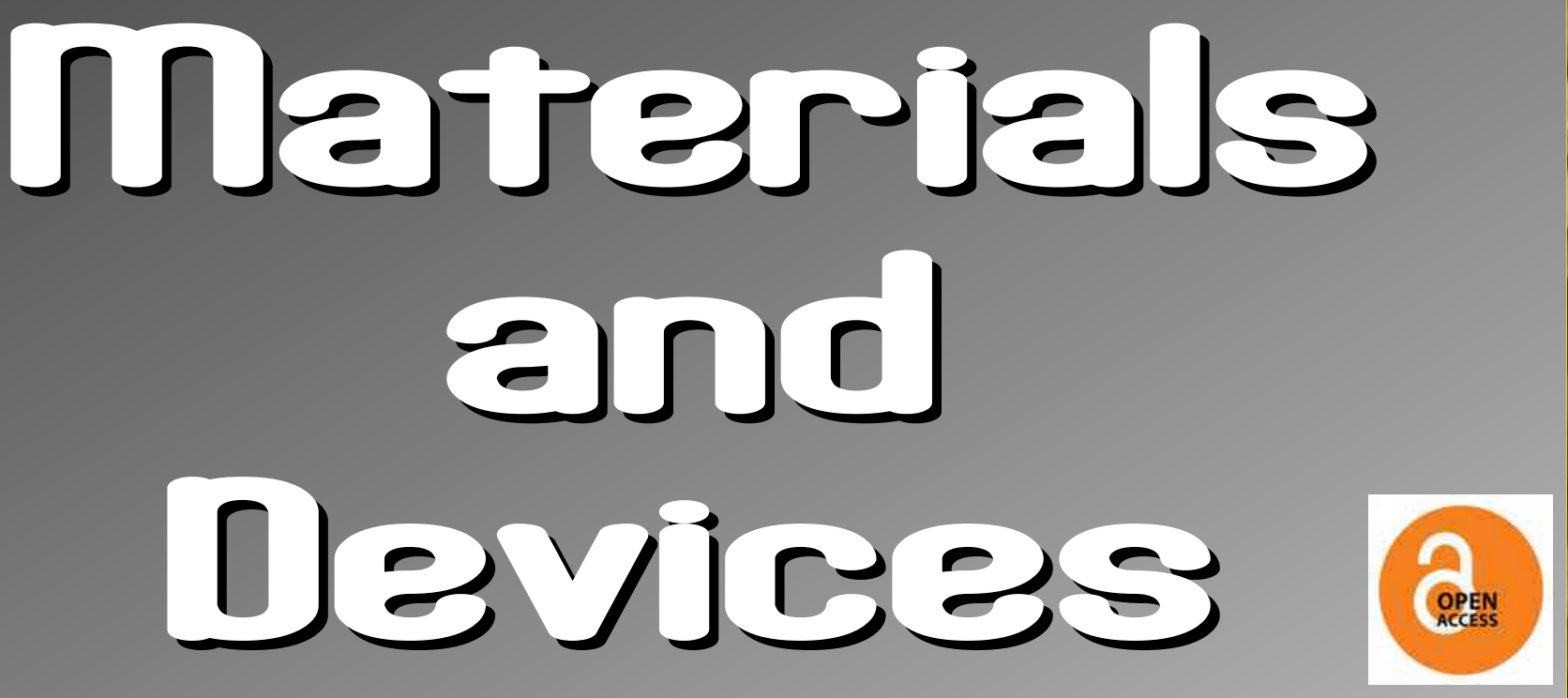

a n international research journal

\title{
CONFERENCE VOLUME
}

Communications presented at the First

Transpyrenean Encounter on Advanced Materials

(TEAM1 - Sète, 4,5,6 jully 2017)

Editor P. Sajit-Grégojre

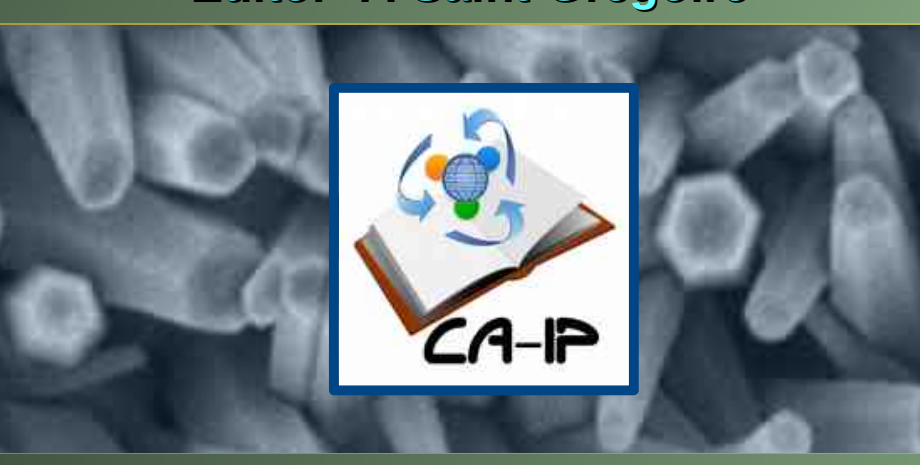

Published by Collaborating

Academics

http://co-ac.com

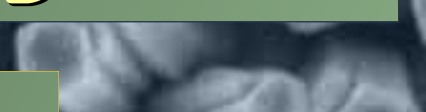



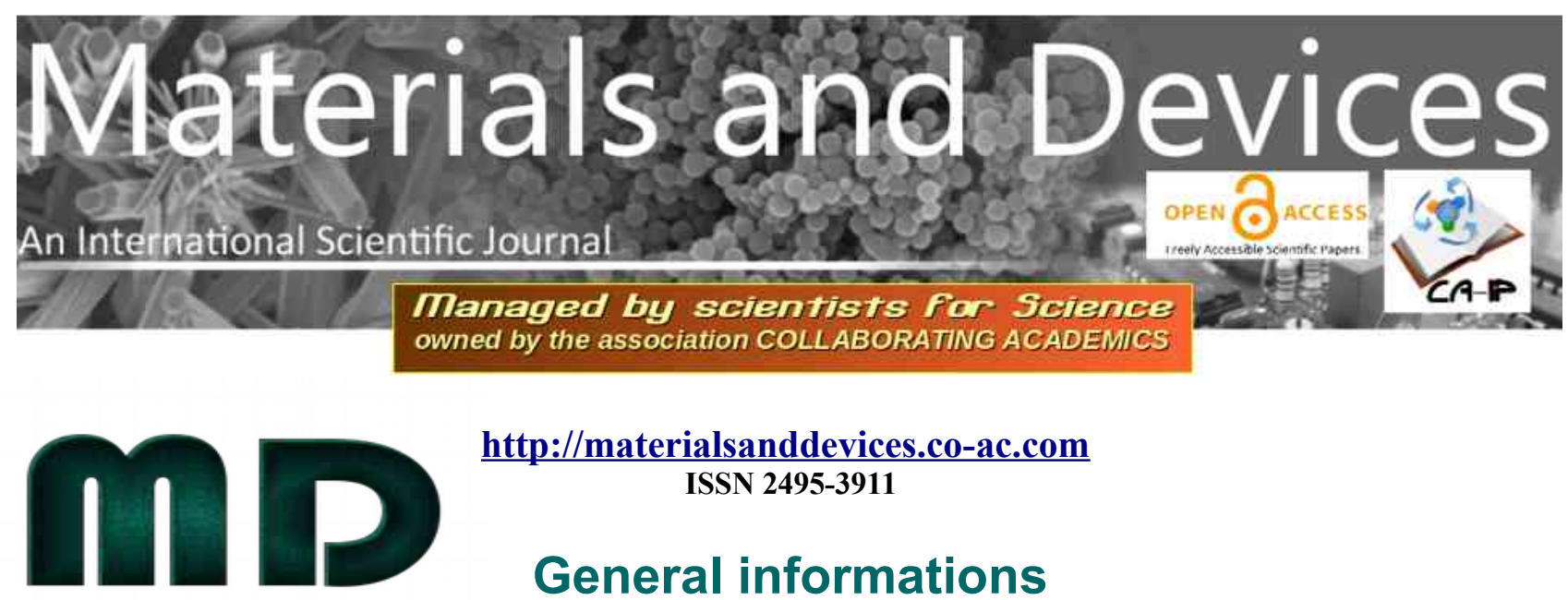

Materials and Devices is a new journal devoted to all aspects of materials and related devices. It is Open Access and free of charges for authors.

Our aim was to create a high quality journal, with a strict peer-review process, and complying with the transparency rules edicted by the DOAJ, COPE,...

\section{Materials and Devices publishes several types of articles :}

- A : regular papers, that should present the results of original research, not published or submitted somewhere else.

- $L$ : short papers, written as letters, focusing on one or few particular aspects, representing a very significant progress, for rapid publication.

- $\mathrm{R}$ : review papers, that presents a summary of results published in literature, on fields covered by the journal.

- $\mathrm{T}$ : technical papers, on the development of laboratory technics and aparatus relevant to studies on materials and related devices. Such papers will present the details of the designed technics, and an example of application in real condition.

- Ur: Unexpected and «negative » results, the journal accepts papers describing unexpected results, or results considered as negative, provided that the original ground arguments are sound, and that a reasonable interpretation can be proposed. Typical examples are : a synthesis process that is generally successful, which aborts in given cases, or give different unexpected but interesting results, results contradicting a theory or a model, etc. The idea to publish such papers is mainly to save time to the scientific community by giving information that is generally not available, except as private communications between researchers.

We are happy to announce these innovations : Section T (technical papers) and Ur (Unexpected and « negative » results are original. They correspond to needs in the scientific community.

- Conf: conference papers: Finally, Materials and Devices may also publish conference proceedings and conference papers in special volumes. This service is not free, organizers of conference interested should contact the journal to know details.

\section{Aims and scope of the journal}

The topics covered by the journal are wide, it aims at publishing papers on :

- all aspects related to materials, namely according to their chemical formula (oxides, fluorides, carbon compounds, ..., organic, inorganic), to their physical properties (conductors, super-conductors, semi-conductors, insulators, dielectrics,...), to their nature (crystalline or amorphous materials, liquid crystals, modulated systems, aperiodic materials, nanomaterials and nanostructured materials)... or environmental type (ecomaterials), or according to some specific applications. Papers on biomaterials, geomaterials, archeomaterials or on studies of ancient materials are also welcome. A particular attention is also paid on environmental studies related with materials. Authors are also encouraged to submit papers on theoretical studies applied to materials, including pure mathematical approaches, physical approaches, models, numerical simulations, etc.

- devices in a wide sense. However, concerning Devices, the scope is restricted to those integrating particular materials (for instance memories based on some specific magnetic materials) or category of materials. Papers on all types of such devices are welcome. 


\section{Policy of the journal}

Materials and Devices is an Open Access (*) journal which publishes original, and peer-reviewed papers accessible only via internet, freely for all. Your published article can be freely downloaded, and self archiving of your paper is allowed!

We apply «the principles of transparency and best practice in scholarly publishing " as defined by the Committee on Publication Ethics (COPE), the Directory of Open Access Journals (DOAJ), and the Open Access Scholarly Publishers Organization (OASPA). The journal has thus been worked out in such a way as complying with the requirements issued by OASPA and DOAJ in order to apply to these organizations.

Evaluation - peer-reviewing : After reception, the paper is sent to two reviewers for evaluation. In case of divergent opinions of reviewers, the editor-in-chief sends the paper to a third reviewer and then gives a final decision based on all reports. Reviewers are asked to reply within three weeks to warranty a fast publication process.

Copyright on any article in Materials and Devices is retained by the author(s) under the Creative Commons (Attribution-NonCommercial-NoDerivatives 4.0 International (CC BY-NC-ND 4.0)), which is favourable to authors.

$\left({ }^{*}\right)$ An open access journal means that all content is freely available without charge to the user or his/her institution. Users are allowed to read, download, copy, distribute, print, search, or link to the full texts of the articles in this journal without asking prior permission from the publisher or the author. This is in accordance with the BOAI definition of open access.

\section{International editorial board}

Orientation of the journal, choice of reviewers, special issues, editorial policy, etc, are discussed by the international editorial board.

\section{List of members}

\section{Algeria}

Mokhtar BOUDISSA, Professor Researcher, Dpt EBT, ENMC Laboratory, Faculté de Technologie, Université F. Abbas SETIF-1, Sétif 19000 - boudi44@yahoo.fr

Brazil

Paulo T.C. FREIRE, Full professor, Universidade Federal do Ceará, Fortaleza - tarso @ fisica.ufc.br

José DE LOS SANTOS GUERRA, Professor, Instituto de Física, Universidade Federal de Uberlandia (UFU), Uberlandia - jsantosguerra@gmail.com

\section{Burkina faso}

Dieudonné Joseph BATHIEBO, Full professor, University of Ouagadougou - djbathiebo@gmail.com

\section{Canada}

Zuo-Guang YE, Professor, Simon Fraser University, Burnaby, BC - zye @ sfu.ca

\section{Cuba}

Aimé PELÁIZ BARRANCO, Full professor, Physics Faculty, Havana University - pelaiz@fisica.uh.cu Maria SÁNCHEZ, Full professor, Faculty of Physics, University of Havana - maruchy @ fisica.uh.cu Elena VIGIL, Full professor, Physics Fac. - Materials Sc. \& Tech. Inst. (IMRE), University of La Habana, and Solar Energy Cathedra Chairperson, Cubasolar-U.H. - evigil @ fisica.uh.cu

\section{Czech Republic}

Ivan GREGORA, Institute of Physics, Czech Academy of Science, Prague - gregora@fzu.cz Vacláv JANOVEC, emeritus professor, Prague

\section{Denmark}

Heloisa BORDALLO, Associate Professor, Niels Bohr Institute - University of Copenhagen

\section{France}

Patrice BOURSON, Professor, LMOPS Université de Lorraine - Centralesupelec 2 rue E. Belin 57070 Metz patrice.bourson@univ-lorraine.fr 
Alain CLAVERIE, Research Director, CEMES/CNRS Toulouse, and private consultant to several companies (microelectronics, areospace) -

claverie@cemes.fr

Pierre SAINT-GRÉGOIRE, Full professor, Universities of Toulon and Nîmes, president of Collaborating Academics, https://fr.linkedin.com/in/saint-gregoirepierre-5bb6372b

pstgregoire@gmail.com

Philippe SCIAU, Senior Scientist,

CEMES-CNRS, 29 rue J. marvig, 31055

Toulouse philippe.sciau@cemes.fr

Georges ZISSIS, Professor, Université Toulouse 3 - Paul Sabatier; Laboratoire LAPLACE UMR 5213, Toulouse georges.zissis@laplace.univ-tlse.fr

\section{Germany}

Lukas M. ENG, TU Dresden, Institute of Applied Physics, and also, Center for Advancing Electronics Dresden lukas.eng@tu-dresden.de

\section{India}

Amit DAS, doctor, Solid state physics division, Bhabha Atomic Research Centre, Trombay, Mumbai 400085

SM YUSUF, Head, Magnetism Section, and Professor at Homi Bhabha National Institute, Solid state physics division, Bhabha Atomic Research Centre, Trombay, Mumbai 400085

\section{Israë|}

Gil ROSENMAN, The Henry and Dinah Krongold Chair of Microelectronics, School of Electrical Engineering-Physical Electronics,

Faculty of Engineering, Tel Aviv University, Ramat Aviv - gilr@eng.tau.ac.il

\section{Italy}

Luca REBUFFI, X-ray Optics and Spectroscopy Laboratory Supervisor, Elettra-Sincrotrone Trieste S.C.p.A., Trieste luca.rebuffi@elettra.eu

\section{Japan}

Emilio J. JUAREZ-PEREZ, Researcher, Energy Materials and Surface Sciences Unit. Okinawa Institute of Science and Technology Graduate University (OIST) 1919-1 Tancha, Onna-son, Okinawa, 904-0495 - ej.juarezperez@oist.jp , http://ej-juarezperez.home.oist.jp/

\section{Kazakhstan}

Koblandy TURDYBEKOV, Head of the Department of Physics, Karaganda State Technical University, Karaganda xray-phyto@yandex.kz

\section{Mexico}

A. Guillermo CASTELLANOS-GUZMÁN, Professor-Researcher, DIP CUCEI Universidad de Guadalajara, Guadalajara Jal. - gcastel@cucea.udg.mx

\section{Moldova}

Anatolie SIDORENKO, Director, Institute of Electronic Engineering and Nanotechnologies "D.GHITU" ASM anatoli.sidorenko@nano.asm.md, anatoli.sidorenko@kit.edu

\section{Morocco}

Abdelhai RAHMANI, Professor, Physics Department, Faculty of Sciences, Meknes rahmani614@gmail.com / a.rahmani@flsh.umi.ac.ma

\section{People Republic of China}

Yang GAN, Professor, Department head, Harbin Institute of Technology, Harbin -

- ygan@hit.edu.cn

Qinghui JIANG, Assoc Professor, State Key Laboratory of Material Processing and Die \& Mould Technology, and School of Materials Science and Engineering, Huazhong University of Science and Technology, Wuhan 430074 -

ghjiang@hust.edu.cn

Zhifu LIU, Professor, CAS Key Lab of Inorganic Functional Materials and Devices, Shanghai Institute of Ceramics, Chinese Academy of Sciences - $\underline{\text { liuzf@mail.sic.ac.cn }}$

Xiaoyong WEI, Professor, Electronic Materials Research Laboratory (EMRL)

Xi'an Jiaotong University, Xi'an 710049 - wdy@mail.xjtu.edu.cn

Poland

Maria ZAPART, Institute of Physics, Faculty of Production Engineering and Materials Technology, Czestochowa University of Technology - zapart@wip.pcz.pl 
Boris DARINSKII, Professor, Voronezh State University, University sq.1, Voronezh 394006 - darinskii@mail.ru

Alexander SIDORKIN, Professor, Voronezh State University, University sq.1, Voronezh 394006 sidorkin@phys.vsu.ru

Alexander SIGOV, Professor, Head of Condensed Matter Physics Chair, President of the University, Moscow Technological University, Moscow - sigov@mirea.ru

Mikhail SMIRNOV, Professor, Physical Department, St. Petersburg State University - smirnomb@rambler.ru Alexander VTYURIN, deputy director, head of Raman spectroscopy group, Kirensky Institute of Physics, Krasnoyarsk vtyurin@iph.krasn.ru

Issakha YOUM, Professor, Department of Physics, FST, University Cheikh Anta DIOP de Dakar, Dakar-Fann

\section{Singapore}

Pooi See LEE, Professor, Nanyang Technological University, Singapore, pslee@ntu.edu.sg

\section{South Africa}

Malik MAAZA, Chair, UNESCO UNISA Africa Chair in Nanosciences, College of Graduate Studies, UNISA, Pretoria, \& NANOAFNET, iThemba LABS, National Research Foundation of South Africa, Faure, Western Cape -

Maaza@tlabs.ac.za,Maazam@unisa.ac.za

\section{Spain}

Javier PIQUERAS, Professor, Universidad Complutense de Madrid Carmen ARAGÓ, Full Professor, Dpt. Física de Materiales, Universidad Autónoma de Madrid carmen.arago@uam.es

Paloma FERNÁNDEZ, Full professor, Department Materials Physics, Fac. of Physics, University Complutense, Madrid arana@fis.ucm.es

$\underline{\text { Togo }}$

Kossi NAPO, Professor, UNESCO Chair on Renewable energies, Faculty of Sciences, University of Lomé silnapo@yahoo.fr

\section{Ukraine}

Yulian VYSOCHANSKII, Professor, Uzhgorod National University, Uzhgorod - vysochanskii@gmail.com

\section{United Kingdom}

James F. SCOTT, Depts. of Chemistry and Physics, St. Andrews University, St. Andrews, Fife, UK KY16 9ST - Jfs4@standrews.ac.uk:

\section{USA}

Michael D. HAMPTON, Professor, Department of Chemistry, University of Central Florida, Orlando, FL 32816

Alexei GRUVERMAN, Professor of Physics, University of Nebraska-Lincoln - agruverman2@,unl.edu

Anirudha V. SUMANT, Ph.D., Materials Scientist, Center for Nanoscale Materials, Argonne National Laboratory, 9700 S.

Cass Ave., Building 440, Room A-127, Argonne, IL 60439 - sumant@anl.gov , Linkedln Profile:

http://www.linkedin.com/in/anisumant

Editor-in-Chief:

Pierre SAINT-GRÉGOIRE (France) - pstgregoire@gmail.com

People interested in this project are welcome ! Contact us to submit your proposals, ideas, suggestions, or to get involved in some actions ! 
Materials and Devices (ISSN 2495-3911) is a new journal, and as such, is not yet indexed. However in future we shall consider as a priority task, to reach a significant impact factor for this journal.

\title{
Collaborating Academics NGO
}

Materials and Devices is owned by the non governmental non profit organization COLLABORATING ACAMICS, an international NGO located in France, that works for scientific communication (organization of meetings, workshops, etc) and development of science. During the launching period authors are encouraged to join the NGO Collaborating Academics (admission fee

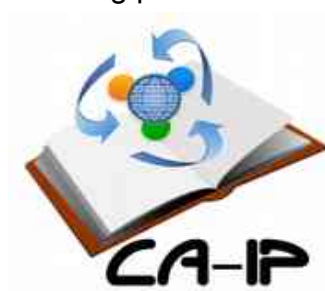
$15 € /$ year) that supports the journal, in order to help reaching financial stability.

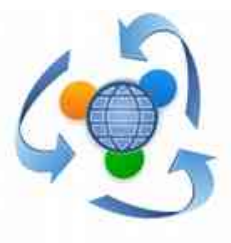

\section{Collaborating Acadernics}

http://co-ac:com

COLLABORATING ACADEMICS has launched Collaborating Academics - International Press. CAIP is a collaborative project led by academics and scholars. The main idea is to appropriate the scientific edition in its Open Access form, and keep it free as much as possible.

These structures base their activities on volunteerism and you are welcome if you are interested in joining us!

\section{To get involved:}

Register as potential reviewer/reader/author in the site of the journal : $\underline{\text { http://materialsanddevices.co-ac.com }}$

Join Collaborating Academics : http://co-ac.com and propose ideas !

Submit papers !

Submit your paper on line at http://materialsanddevices.co-ac.com

Contact us at : contact@co-ac.com

Publisher : COLLABORATING ACADEMICS

French association (loi 1901) registered Nr W343019101 (Préfecture de l’Hérault).

No SIRET: 81488347600016 - APE 9499Z

Address : 14, Av Frederic Mistral, 34110 Frontignan, France

Contact : + 33675640229 - email : contact@co-ac.com

\section{Advertising of free/open source softwares}

\author{
Scientists need efficient, robust, reliable operating systems... Use Linux!
}

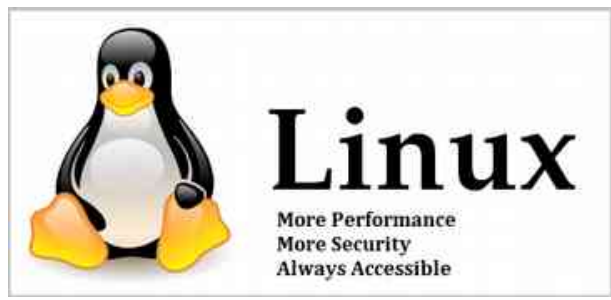




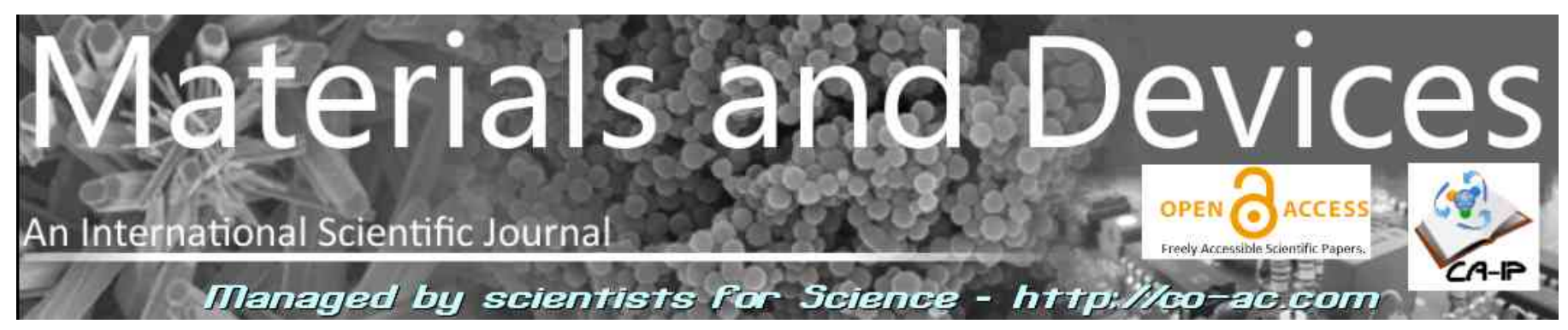

\section{Advertising of free/open source softwares}

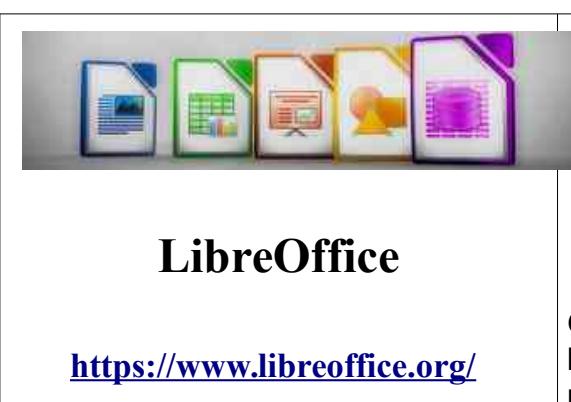

LibreOffice is a powerful office suite its clean interface and feature-rich tools help you unleash your creativity and enhance your productivity. LibreOffice includes several applications that make it the most powerful Free and Open Source office suite on the market: Writer (word processing), Calc (spreadsheets), Impress (presentations), Draw (vector graphics and flowcharts), Base (databases), and Math (formula editing).

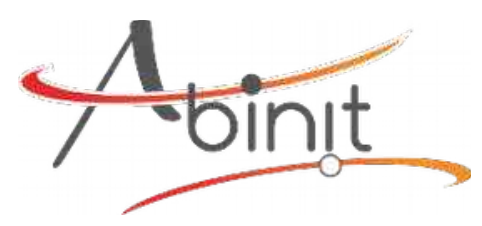

http://www.abinit.org/

ABINIT is a package whose main program allows one to find the total energy, charge density and electronic structure of systems made of electrons and nuclei (molecules and periodic solids) within Density Functional Theory (DFT), using pseudopotentials and a planewave or wavelet basis.. learn more in the internet site!

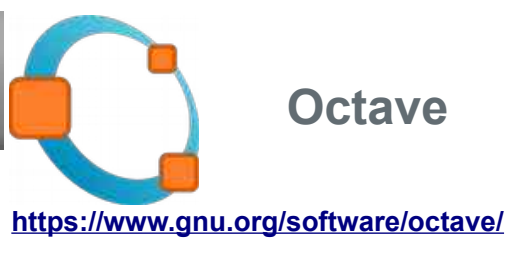

GNU Octave is a high-level interpreted language, primarily intended for numerical computations. It provides capabilities for the numerical solution of linear and nonlinear problems, and for performing other numerical experiments. It also provides extensive graphics capabilities for data mathematical functions. It has a high visualization and manipulation. Octave level programming language allowing is normally used through its interactive access to advanced data structures, 2command line interface, but it can also $D$ and 3-D graphical functions.

be used to write non-interactive

programs. The Octave language is A large number of functionalities is quite similar to Matlab so that most included in Scilab.

programs are easily portable.

\section{8? Elmer}

\section{https://csc.fi/web/elmer/elmer}

Elmer is an open source multiphysical simulation software mainly developed by CSC - IT Center for Science (CSC). Elmer development was started 1995 in collaboration with Finnish Universities, research institutes and industry. After its open source publication in 2005 , the use and development of Elmer has become international.

Elmer includes physical models of fluid dynamics, structural mechanics, electromagnetics, heat transfer and acoustics, for example. These are described by partial differential equations which Elmer solves by the Finite Element Method (FEM).

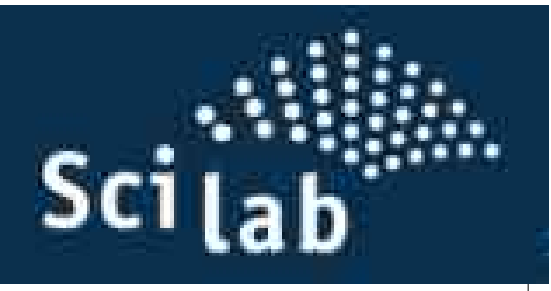

http://www.scilab.org/en

Scilab is free and open source software for numerical computation providing a powerful computing environment for engineering and scientific applications. Scilab includes hundreds of

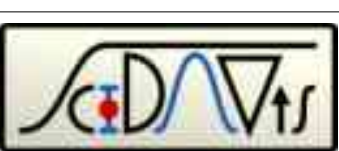

\section{SciDAVis}

http://scidavis.sourceforge.net/ SciDAVis is a free application for Scientific Data Analysis and Visualizat

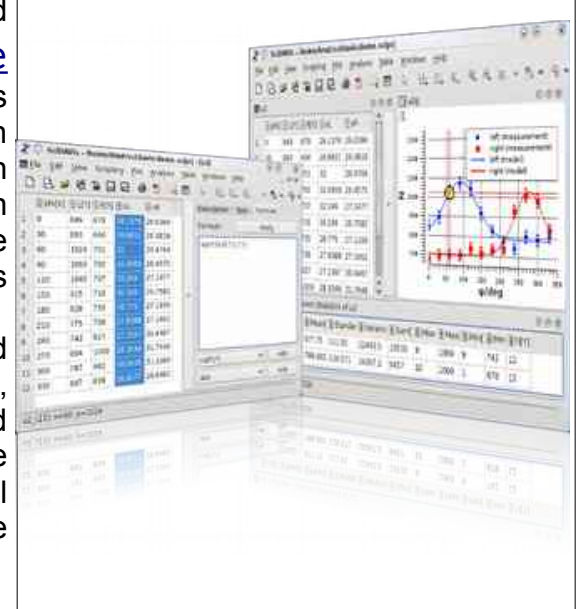




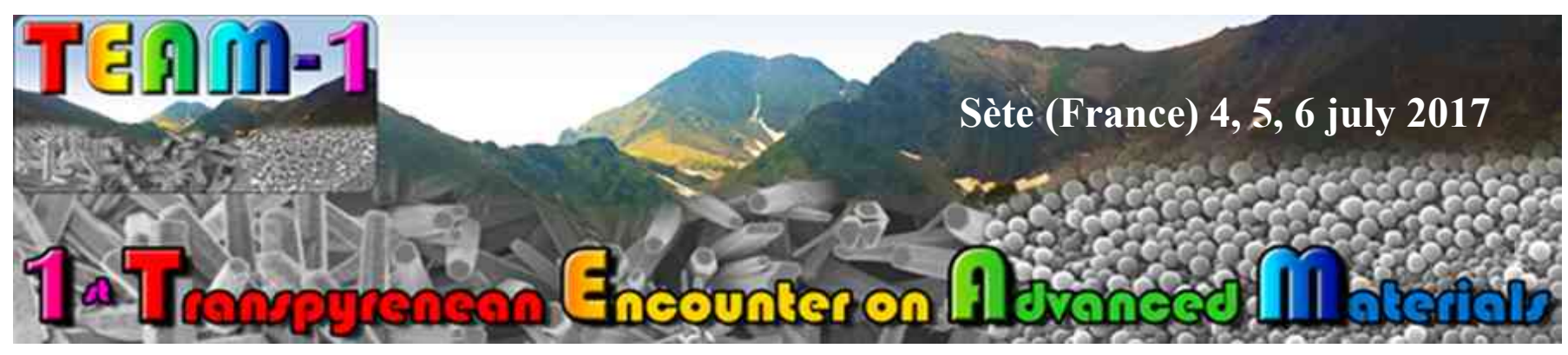

\section{http://teaml.co-ac.com}

\section{Aims and participants}

The Transpyrenean Encounter on Advanced Materials aims at establishing or reinforcing contacts and collaborations between groups of France, Spain, and Portugal, in the fields of advanced materials, and related topics. The encounter is also open to participants from other countries, wishing to construct or having collaborations with groups of the above countries. We hope that this meeting, TEAM-1, will open a series of encounters, and the preparation of TEAM-2 will be discussed by the binational permanent committee in near future.

\section{Covered topics}

All topics related to advanced materials of different types are relevant ; in particular presentations may belong to the following categories : advanced electronic, optical, and optoelectronic materials, advanced materials for energy, advanced engineering materials, advanced materials for biomedical applications, nanomaterials and low dimensional materials, miscellaneous advanced materials, smart materials, advanced materials in systems, and also infrastructures for Materials Characterization and advanced characterisation techniques.

\section{Local committees}

\section{GENERAL ORGANIZER}

SAINT-GREGOIRE Pierre Universities of Toulon and Nîmes / Collaborating Academics (France)

\section{CHAIR COMMITTEE}

$\begin{array}{ll}\text { CLAVERIE Alain } & \text { CEMES-CNRS, Toulouse, France } \\ \text { GAGOU Yaovi } & \text { University of Picardie, Amiens (France) } \\ \text { SAINT-GREGOIRE Pierre } & \text { Universities of Toulon and Nimes/ Collaborating Academics (France) }\end{array}$

\section{ORGANIZING COMMITTEE}

$\begin{array}{ll}\text { ALLOUCHE Billal } & \text { Leti, CEA Grenoble (France) } \\ \text { ASBANI Bouchra } & \text { PMN/ST2E- IMN, Nantes (France) } \\ \text { FRÉMY Marie-Angèle } & \text { University of Toulon (France) } \\ \text { PÉREZ Annie } & \text { University of Aix-Marseille (France) }\end{array}$




\section{Scientific committees}

\section{INTERNATIONAL SCIENTIFIC COMMITTEE}

The scientific committee is constituted of about 35 scientists from France, Portugal, Spain, and few other countries, working in the field of advanced materials. The role of this international committee is to discuss the scientific orientation of the encounter(s), propose invited talks, topics, etc.

\section{List of members :}

ALONSO, Julio A., University of Valladolid, Valladolid, Spain; BARON Thierry, LTM - UMR 5129 CNRS-UGA, GRENOBLE, France ; BERNARD Samuel, CNRS/IEM, MONTPELLIER, France ; BOURGES Philippe, Laboratoire Léon Brillouin - LLB - CEN-CEA, SACLAY, France ; BUCHAILLOT Lionel, IEMN Cite scientifique, VILLENEUVE D'ASCQ, France ; BUSTARRET Etienne, CNRS, Institut Néel, GRENOBLE, France ; CASANOVE Marie-José, CEMES-CNRS, TOULOUSE, France; CATALAN, Gustau, ICREA-ICN2, BARCELONA, Spain ; CAVALEIRO, Albano, University of Coimbra, COIMBRA, Portugal ; CHAUDRET Bruno, LPCNO, UMR 5215 INSA-CNRS-UPS, INSA, TOULOUSE, France ; CLAVERIE Alain, CEMES-CNRS, TOULOUSE, France; COUTAZ Jean-Louis, IMEP-LAHC, University Savoie Mont Blanc, LE BOURGET DU LAC, France ; DE TERESA NOGUERAS, José Maria, CSIC-UNIVERSITY OF ZARAGOZA, ZARAGOZA, Spain ; DUGOURD Philippe, ILM, University Lyon1, LYON, France ; FERNANDEZ SANCHEZ Paloma, Department Física de Materiales, Fac. of Physics, University Complutense, MADRID, Spain ; GAFFET Eric, IJL, University of Lorraine, NANCY, France; GAGOU Yaovi, LPMC, University of Picardie Jules Verne, AMIENS, France ; KADRI Abderrahmane, LEMOP, University of Oran, ORAN, Algeria ; MAGÉN, César, University of Zaragoza, Fundación ARAID, ZARAGOZA, Spain ; MAIGNAN Antoine, CRISMAT, ENSICAEN, CAEN, France ; MANO João F., University of Aveiro, AVEIRO, Portugal ; MARÉ Thierry, IUT saint Malo, University Rennes1, LGCGM, RENNES, France ; MARTINGAGO, Jose A., ICMM-CSIC, MADRID, Spain ; MAUREL François, ITODYS, University Paris Diderot , PARIS, France ; MONTEIRO, Teresa, Department of Physics and I3N, University of Aveiro, AVEIRO, Portugal ; MULLER Pierre, CINAM, University Aix-Marseille, MARSEILLE, France ; PELÁlZ-BARRANCO, Aimé, Ferroic Materials Group, Physics Faculty, Havana University, LA HABANA, Cuba; REMIENS Denis, IEMN- DOAE - University of Valenciennes and Hainaut Cambrèsis (UVHC) and USTL, VALENCIENNES, France; SAINT-GRÉGOIRE Pierre, MIPA laboratory, Universities of Toulon and Nîmes, NÎMES/TOULON, France; VILATELA, Juan José, IMDEA Materials, MADRID, Spain ; ZUNIGAPEREZ, Jesus, CRHEA, CNRS, VALBONNE, France.

\section{PERMANENT RESTRICTED COMMITTEE}

Besides the international committee, TEAM organization involves a permanent restricted committee the role of which is to discuss the programmation of next encounters, decide about periodicity of encounters, choose among different propositions (date, place, etc). Composition: ALONSO Julio, CLAVERIE Alain, FERNANDEZ SANCHEZ Paloma, GAGOU Yaovi, MONTEIRO Teresa, SAINT-GREGOIRE Pierre

\section{Logos design : Anna Cantaluppi}

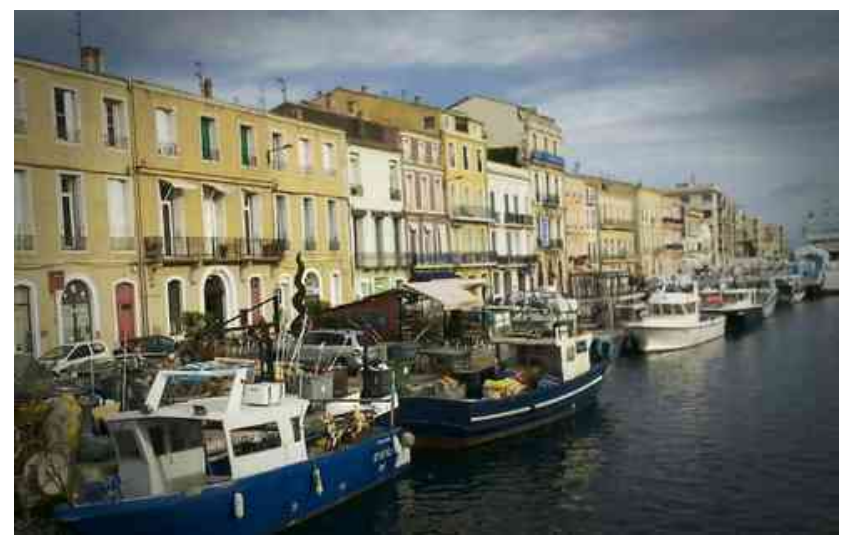

TEAM1 - presentation 


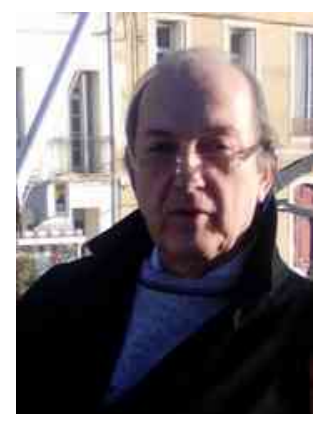

\section{First Transpyrenean Encounter on Advanced Materials : forewords}

The idea to organize an event having as main goal to favour and develop contacts and collaborations on advanced materials on both sides of pyrenean mountains has emerged progressively through informal discussions at the occasion of various meetings between individual scientists. Finally the situation has accelerated few months ago, with a proposition to organize it during the summer 2017, under the aegis of the association COLLABORATING ACADEMICS (http://co-ac.com).

It was a real challenge to succeed to be ready in time : first we had to think to the structure and general organization, then to constitute the local committees, the permanent committee, and the scientific committee. It took time to do this, and when we finally had a complete list of members, we had a rather short time to discuss about the content of TEAM-1.

As a consequence everything was not perfect, but we did our best to launch and organize TEAM-1, which had the advantage to "start the process ", to make the original idea real, and to define the basis of further meetings of the series, if there is a continuation, which we hope !

TEAM-1 has gathered less than 40 participants, but a meeting with such a reasonable number of persons is an advantage to interchange, know each other, and discuss about collaborations. Most of participants were of course from France, Portugal, and Spain, but few other countries had representants, like Algeria, Cuba, Poland, and Senegal that we had the pleasure to welcome. We hope to see in future other meetings of the series being organized in various places, and to see the development of initial ideas to allow the setup of scientific networks on various topics on advanced materials.

This first encounter has given the opportunity to exchange about numerous fields on covered topics, having the advantage to attract attention of participants to other research problems than their own, thus favouring contacts between researchers of different specialities. May this series of meetings contribute to meet the challenges and needs of humanity in the next decades, in which the role of advanced materials should be determinant in many respects!

Before closing these forewords, I would like to thank all those who made this meeting possible : members of organizing committees, members of the staff of Lycée Charles de Gaulle who did their best to host the encounter, the University Complutense de Madrid for financial support, and all participants for their interesting and good quality communications !
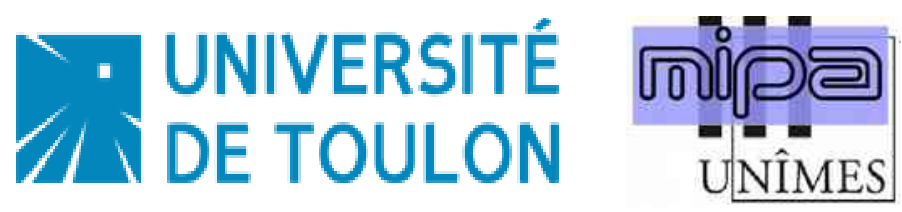

\section{Prof. Pierre Saint-Grégoire}

MIPA Laboratory

Universities of Toulon and Nîmes

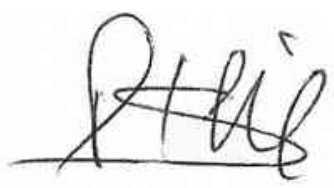




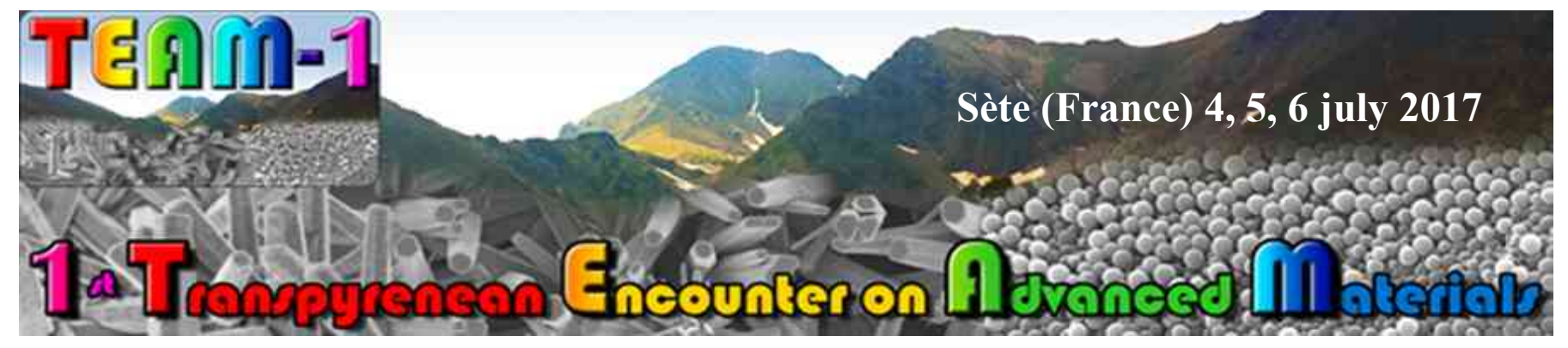

\author{
http://teaml.co-ac.com
}

\title{
COMMUNICATIONS
}




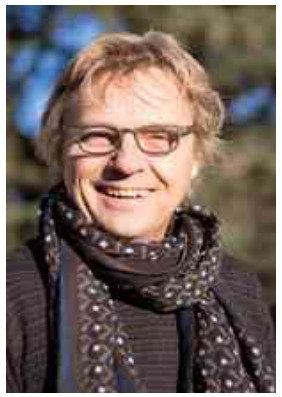

\title{
Electron Holography for the quantitative measurements of electric and magnetic properties in nanostructures
}

\author{
E. Snoeck, C. Gatel, L. A. Rodríguez, A. Masseboeuf
}

CEMES-CNRS 29, rue Jeanne Marvig, B.P. 94347, F-31055 Toulouse Cedex, France.

Corresponding author: snoeck@cemes.fr

Keywords : ELECTRON HOLOGRAPHY, MAGNETIC DOMAIN WALL, ELECTRIC CHARGES

\begin{abstract}
Electron holography $(\mathrm{EH})$ is powerful TEM method particularly efficient for the quantitative studies of local electrostatic and magnetic fields with spatial resolution of the order of few nanometers and over fields of view as large as few microns [1]. In addition, EH allows performing in-situ measurements for the analysis of magnetic reversal processes as function of external applied field at various temperatures or of domain wall (DW) motion under the application of an electrical pulse.

The basics of $\mathrm{EH}$ and of the experimental procedure will be first presented and we will illustrate the capabilities of $\mathrm{EH}$ to measure the number of electric charges trapped in an insulating nanostructure [2].

In a second part, we will present recent $\mathrm{EH}$ results obtained on the magnetic configuration change in Fe nanocubes for sizes varying between 20 to $30 \mathrm{~nm}$ [3] and on the magnetic domain wall configuration in diameter-modulated FeCoCu nanowires [4]. We will discuss these results combined with micro-magnetic simulations.
\end{abstract}

\section{References:}

[1] Magnetic Mapping Using Electron Holography E. Snoeck and C. Gatel in Transmission Electron Microscopy in Micronanoelectronics ed. A. Claverie, Editeur : ISTE Ltd and John Wiley \& Sons Inc (2012)

[2] Counting elementary charges on nanoparticles by electron holography, C. Gatel, A. Lubk, G. Pozzi, E. Snoeck, and M.J. Hÿtch, Phys. Rev. Lett. 111, 025501 (2013)

[3] Size specific spin configurations in single iron nanomagnet: from flower to exotic vortices. C. Gatel, F. Bonilla, E. Snoeck, B. Warot-Fonrose, B. Chaudret, L-M. Lacroix, and T. Blon Nano Lett., 2015, 15 (10), pp 6952-6957

[4] Quantitative Nanoscale Magnetic Study of Isolated Diameter-Modulated FeCoCu Nanowires L. A. Rodriguez, C. Bran, D. Reyes, E. Berganza, M. Vazquez, C. Gatel, E. Snoeck and A. Asenjo ACS Nano, 2016, 10 (10), pp 9669-9678`
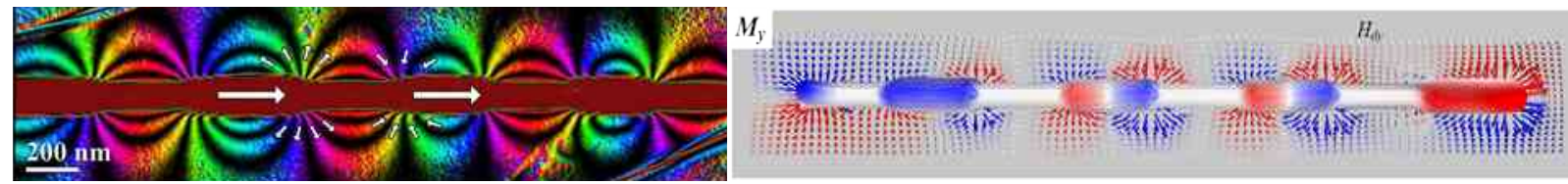


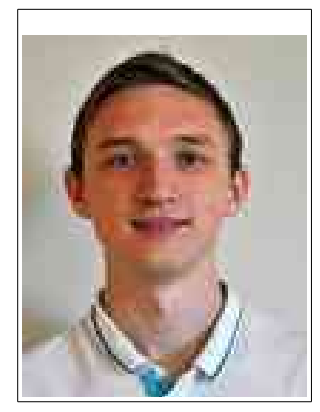

\title{
Macroscopic CNT fibers as multifunctional material for large-area flexible all-solid-state EDLC
}

\author{
E. Senokos (1), V. Reguero (2), L. Cabana (3), J. Palma (4), R. \\ Marcilla (5), J. J. Vilatela (6)
}

(1) IMDEA Materials Institute, Spain, evgeny.senokos@imdea.org

(2) IMDEA Materials Institute, Spain, victor.reguero@imdea.org

(3) IMDEA Materials Institute, Spain, laura.cabana@imdea.org

(4) IMDEA Energy Institute, Spain, jesus.palma@imdea.org

(5) IMDEA Energy Institute, Spain, rebeca.marcilla@imdea.org

(6) IMDEA Materials Institute, Spain, juanjose.vilatela@imdea.org

Juan Jose Vilatela: juanjose.vilatela@imdea.org

Keywords : CARBON NANOTUBE FIBERS, ALL-SOLID SUPERCAPACITOR, ENERGY STORAGE, POLYMER ELECTROLYTE, STRUCTURAL COMPOSITE

Growing interest to multifunctional energy storage systems providing high electrochemical properties alongside with excellent flexibility and capability to withstand static and dynamic mechanical stresses demands new electrode materials and architectures. Carbon nanotube (CNT) fibres is considered as highly appealing candidate material for flexible energy storage owing to their unique combination of excellent electrical conductivity $\left(3.5 \times 10^{5} \mathrm{~S} / \mathrm{m}\right)$, highperformance mechanical properties (specific tensile strengths of $1,5 \mathrm{GPa} / \mathrm{SG}$, modulus of $60 \mathrm{GPa} / \mathrm{SG}$ and toughness of $80 \mathrm{~J} / \mathrm{g})$ and high surface area $\left(260 \mathrm{~m}^{2} / \mathrm{g}\right)$. Here we present a simple method to fabricate large area $\left(100 \mathrm{~cm}^{2}\right)$ all-solid EDLCs made by CNT fibres and ionic liquid-based polymer electrolyte membrane. Electrochemical characterization demonstrate excellent performance of all-solid devices with the maximum gravimetric capacitance, energy and power densities of $28 \mathrm{~F} / \mathrm{g}, 11.4 \mathrm{Wh} / \mathrm{kg}$ and $46 \mathrm{~kW} / \mathrm{kg}$ very similar to those obtained using pure IL, and which can be taken as a benchmark to evaluate the efficiency of the EDLC assembly process. Furthermore, self-standing all-solid EDLCs exhibit excellent cyclic stability over 10000 cycles with capacitance retention more than $96 \%$ at $3.5 \mathrm{~V}$ of applied voltage and $5 \mathrm{~mA} / \mathrm{cm}^{2}$ current density. The EDLC devices can be repeatedly bent and folded $180^{\circ}$ without degradation of their properties. Moreover, bending produces reversible increases in energy density of as much as $25 \%$. Mechanical test of SC devices demonstrate a great perspective to use these materials as structural EDLC. Implementation of the tensile properties of an individual filament in resulting composite would enable achieving specific modulus and strength of approximately 0.37 $\mathrm{GPa} / \mathrm{SG}$ and $18 \mathrm{GPa} / \mathrm{SG}$, respectively. 


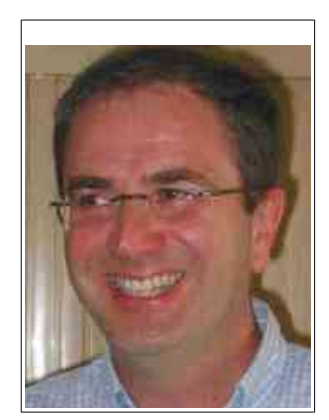

\title{
Materials and methods, using oxalic precursors. Applications to soldering and component manufacturing by selective laser decomposition
}

\author{
Ph. Tailhades (1), I. Pasquet (1), H. Le Trong (1), V. Baco-Carles (1), L. \\ Presmanes (1), C. Bonningue (1), M. Gougeon (1), K. Kiryukhina (2), V. \\ Conedera (3), P.F Calmon (3), D. Dragomirescu (4), H. Camon (3)
}

(1) Institut Carnot Chimie Balard Cirimat, UMR CNRS 5085, Université de Toulouse, Université Paul Sabatier 118 route de Narbonne, 31062 Toulouse Cedex 9, France.

(2) Centre National d'Etudes Spatiales, 18 Avenue Edouard Belin, 31401 Toulouse Cedex 9, France

(3) LAAS-CNRS, Université de Toulouse, CNRS, 7 avenue du colonel Roche, 31400 Toulouse

(4) LAAS-CNRS, Université de Toulouse, CNRS, INSA, 7 avenue du colonel Roche, 31400 Toulouse

\section{Corresponding author : tailhades@chimie.ups-tlse.fr}

Keywords : OXALATE, SELECTIVE LASER DECOMPOSITION, SOLDERING, PATTERNING, SELECTIVE LASER SINTERING

Transition metal oxalates have very often been used as precursors for the preparation of oxides or metals at moderate temperatures. During the oxalate decomposition, nanoparticles are generally formed. They exhibit a high sinterability, or even lower melting points compared with the bulk state. These properties can be used to form solders at low temperatures, with metals having high bulk melting points, or to directly form oxides or metals by local decomposition of the oxalates in a focused laser beam.

(a)

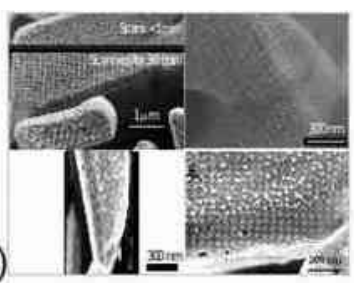

(b)

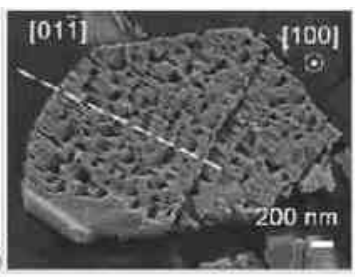

(c)

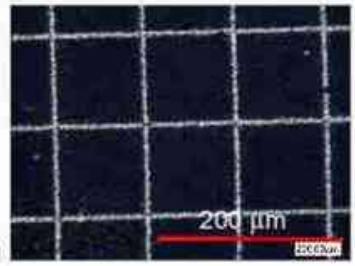

d)

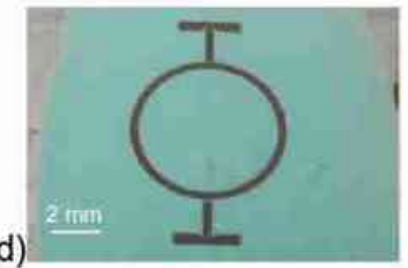

Figure 1 : (a) Illustration of the sensitivity of silver oxalate to decomposition: periodic formation of silver particles under the electron beam of a SEM (b) Formation of Ag nanoparticles inside the oxalate porosity resulting from the thermal decomposition (c) Metallic silver grid obtained by selective laser decomposition of silver oxalate (the remaining oxalate was removed by washing) (d) Copper oxide pattern inside a copper oxalate layer.

This talk details more specifically, the behavior of the silver oxalate and its advantage for the brazing electronic components at low temperature and the shaping of two-dimensional metallic structures, using conventional photolithography machines. Other examples, described and discussed, relate to the production of two-dimensional semiconducing or ferrimagnetic structures based on single or mixed oxides. 


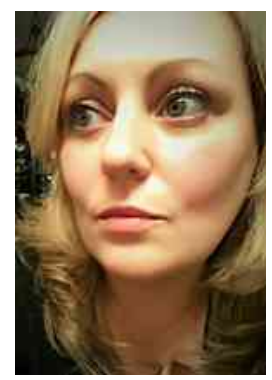

\section{Scanning Thermal Microscopy} THERMAL PROBING AND ACTING AT THE NANOSCALE

\section{J. Pereira (1), J. S. Amaral (2), N. J. O. Silva (3), V. S. Amaral (4)}

(1) CICECO and Physics Department, University of Aveiro, Portugal, mariasapereira@ua.pt

(2) CICECO and Physics Department, University of Aveiro, Portugal, jamaral@ua.pt

(3) CICECO and Physics Department, University of Aveiro, Portugal, nunojoao@ua.pt

(4) CICECO and Physics Department, University of Aveiro, Portugal, vamaral@ua.pt

\section{Corresponding author : mariasapereira@ua.pt}

Keywords : STHM, MICROSCOPY, THERMAL MANAGEMENT, NANO-THERMAL ANALYSIS, ATOMIC FORCE MICROSCOPY (AFM)

Thermal nano-characterization techniques with high spatial resolution are fundamental to address thermal issues which may compromise the performance of miniaturized devices and materials. Scanning thermal microscopy (SThM) is a probing and acting technique based on atomic force microscopy that uses a nano-probe designed to act as a thermometer and a resistive heater. Using a PARK SYSTEMS XE7 Scanning Thermal Microscopy equipment (tip radius $\sim 100 \mathrm{~nm}$, temperature up to $\sim 160^{\circ} \mathrm{C}$, sensitivity $\sim 0.1^{\circ} \mathrm{C}$ and $50 \mathrm{~nm}$ spatial resolution) we present the versatility of the technique taking several approaches to study material properties [1]. SThM's high spatial resolution and ability to perform surface and sub-surface thermal imaging are highlighted in the study of nanocomposite structures with complex inhomogeneities, such as graphene oxide(GO)/poly(lactic acid) (PLA) (Fig. 1). Assisted by the control of the global material's temperature with external heat sources, the nano-probe's thermal sensing and actuating abilities induce local structural transformations in materials such as the ferromagnetic shape memory alloy Ni-Mn-Ga and map the spatial distribution of local martensite-austenite transition temperatures.
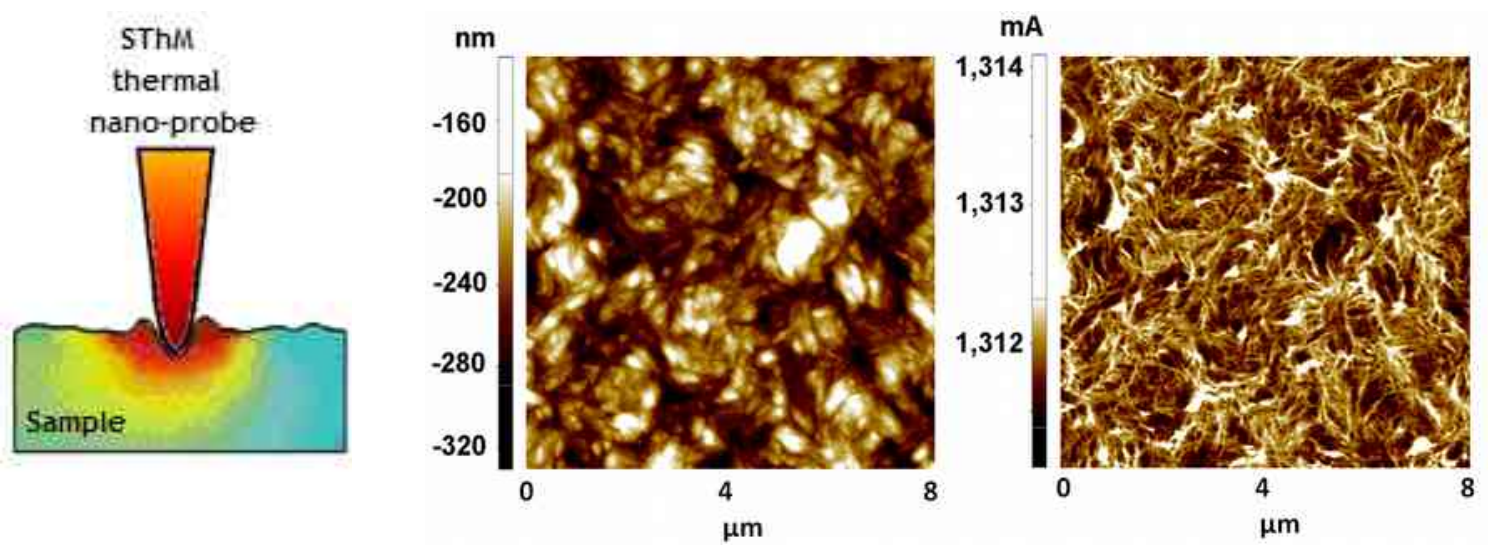

Fig.1 Left: schematic of the SThM thermal nano-probe heating profile when in contact with the sample; Topography (center) and thermal conductivity contrast (TCC) (right) of GO/PLA nanocomposite (TCC scan showing details on entwining of polymeric chains absent from topography scan). Samples provided by Prof. Ana Barros (Univ. Aveiro)

[1] M. J. Pereira, J. S. Amaral, N. J. O. Silva, V. S. Amaral, Microscopy and Microanalysis, V 22, Issue 6 (2016) $1270-1280$ 


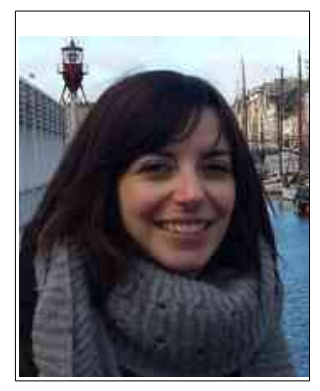

\title{
Piezoelectric ZnO/PVA composite films
}

\author{
C. Mateo-Mateo (1, 2), J. Yuan (1), M.A. Correa-Duarte (2), A. Colin \\ (1), P. Poulin (1)
}

(1) Centre de Recherche Paul Pascal (CRPP), CNRS, Université de Bordeaux, France

(2) Department of Physical Chemistry, Biomedical Research Center (CINBIO), Universidade de Vigo, Spain

Corresponding author: mateo@crpp-bordeaux.cnrs.fr

Keywords : PIEZOELECTRIC, COMPOSITE, FILMS

Piezoelectric energy harvesting [1] is a promising technology for energy recovery from vibration or shock. Although piezoelectric (PZ) materials are used in several applications such as generators, fuel lighters, sensors in automobiles...their use on large scale remains challenging. The main problem relies on the lack of mechanical resistant and efficient materials suitable for new applications.

Herein, we present the hydrothermal synthesis of $\mathrm{PZ} \mathrm{ZnO}$ nanowires (NWs) with high aspect ratio and the fabrication of ZnO/PVA composite films by embedding the ZnO particles in the polymer matrix. The application of an electrical field allows the alignment of the $\mathrm{ZnO}$ NWs giving a strong net macroscopic polarization under stress. Mechanical deformation tests were also performed on the composite films observing the presence of strong voltage peaks that could be related to piezoelectric effects. Other mechanisms related to triboelectric contributions will be discussed.

The combination of the flexible polymer (PVA) with high aspect ratio PZ particles [2] could lead to obtain efficient PZ films with high strength and flexibility.
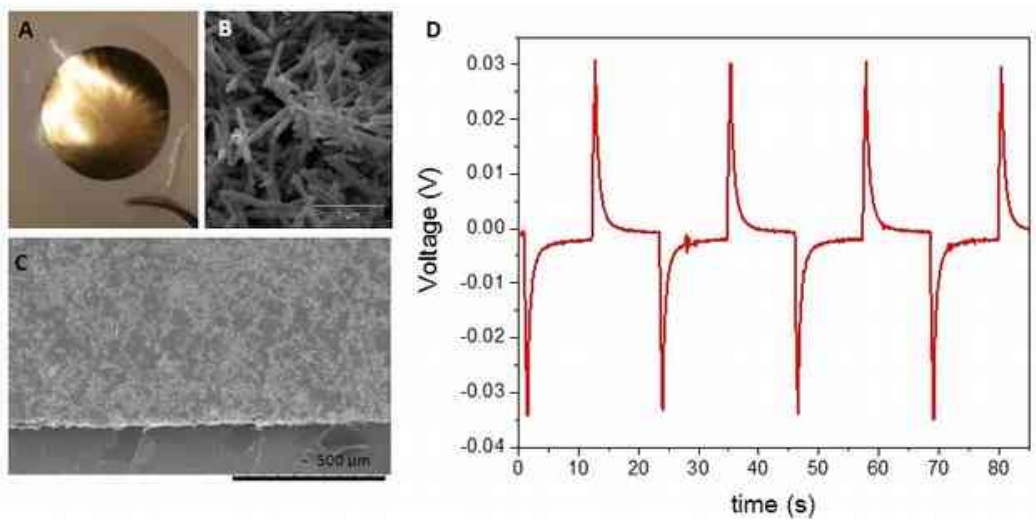

Fig 1. ZnO/PVA freestanding composite film (A) and SEM images of the composite film (B, C). View of the top Au electrode on the composite film (A). Electrical response when the film is mechanically deformed (D).

\section{REFERENCES}

[1] J. Curie, P. Curie, Bulletin de la Société minéralogique de France, vol 3 (1880) 90-93

[2] C. Andrews, Y.R. Lin, H.X. Tang, H.A. Sodano, Journal of Intelligent Material Systems and Structures 22, 6 (2011) 1879-1886 


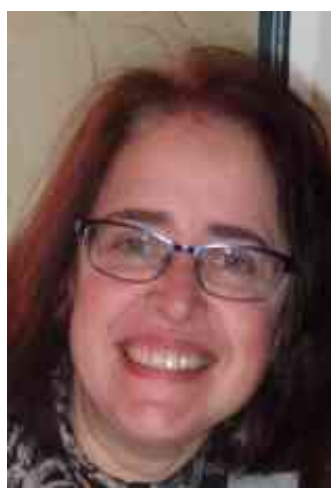

\title{
When high pressure-high temperature synthesis helps to discover new oxides: EXAMPLES FROM MULTIFERROISM AND MAGNETIC FRUSTRATION
}

\author{
P. Zuo $(1,2)$, C. Darie $(1,2)$, C. Goujon $(1,2)$, M. Legendre $(1,2)$, C.V. \\ Colin $(1,2)$, H. Klein $(1,2)$, P. Bordet $(1,2)$ \\ (1) Univ. Grenoble Alpes, Inst NEEL, F-38000 Grenoble, France \\ (2) CNRS, Inst NEEL, F-38000 Grenoble,
}

Corresponding author : celine.darie@neel.cnrs.fr

Keywords : HIGH PRESSURE- HIGH TEMPERATURE, OXIDES, MULTIFERROISM, MAGNETIC FRUSTRATION

In the last decades, high pressure (>1GPa) has been increasingly used in different fields of research ranging from earth science to solid state physics, chemistry and material science. At Institut Néel, Grenoble, a state-of-the-art and unique instrumental park is dedicated to solid-state synthesis, crystal growth and characterization of materials under extreme conditions (Fig.1).

In this contribution we start with a description of these high pressure (up to 15GPa) and high temperature (up to $1500^{\circ} \mathrm{C}$ ) facilities, with an extension to recent developments and new experimental set-up as DTA (Differential Thermal Analysis) and XRD (X-Ray Diffraction).

In a second part, we will present two studies of HP-HT syntheses in the field of research of new materials that are multiferroic or show magnetic frustration, respectively. The case of a new form of a spin liquid phase ${ }^{1} \mathrm{Ba}_{3} \mathrm{NiSb}_{2} \mathrm{O}_{9}$ obtained under high pressure-high temperature will be presented. The second example will show the stabilization of small rare-earth compounds in the series $\mathrm{NaLnCoWO}_{6}(\mathrm{Ln}=$ rare earth), a new class of potentially multiferroic compounds, with the help of HP-HT2.
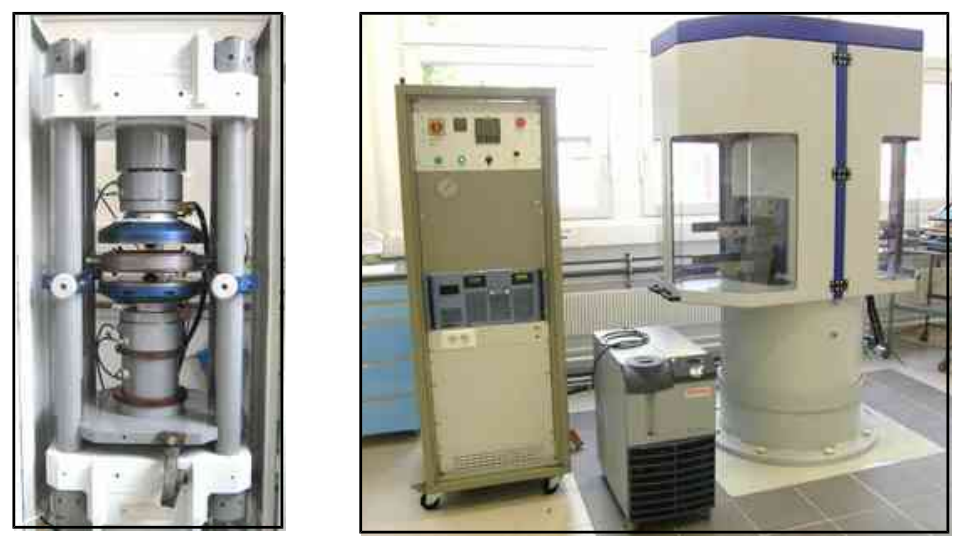

Fig. 1: Belt (left) and Conac (right) devices at Institut Néel

(1) "A new high pressure form of $\mathrm{Ba}_{3} \mathrm{NiSb}_{2} \mathrm{O}_{9}$ ” C. Darie, C. Lepoittevin, H. Klein, S. Kodjikian, P. Bordet, C.V. Colin, O.I.Lebedev, C. Deudon, C. Payen Journal of Solid State Chemistry 237(2016)166-173

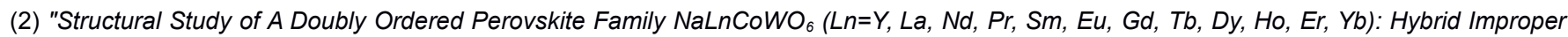
Ferroelectricity in Nine New Members" P. Zuo, C. V. Colin, H. Klein, P. Bordet, E. Suard, E. Elkaim and C. Darie submitted to Inorganic Chemistry 


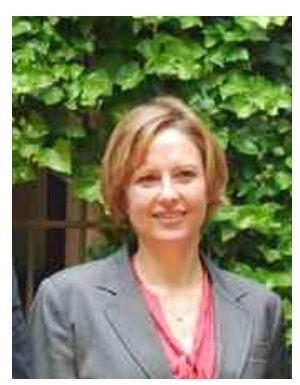

\title{
Diamond interfaces in power devices: Electron microscopy issues
}

\author{
D. Araújo ${ }^{(1)}$, J.C. Piñero(1), F. Lloret ${ }^{(1,2)},{\text { P. } \text { Villar }^{(1)}, \text { M. Gutiérrez }}^{(1)}, M$. \\ Florentin (2), T. Pham $^{(2)}$, D. Eon ${ }^{(2)}$, J. Pernot ${ }^{(2)}$ \\ (1) Departamento de ciencias de los materiales IM y QI, Universidad de Cádiz, 11510 \\ Puerto Real (Cádiz), Spain, daniel.araujo@uca.es \\ (2) Institut Néel, CNRS-UJF, av. Des Martyrs, 38024 Grenoble (France) \\ (3) Univ. Grenoble Alpes, F-38000 Grenoble (France) \\ (4) Institut Universitaire de France, 103 Boulevard Saint Michel, 75005 Paris (France)
}

Corresponding author: daniel.araujo@uca.es

Keywords : DIAMOND, POWER DEVICES, ELECTRON MICROSCOPY, MPCVD, TEM

The growing interest on the applications of diamond for power devices relies in its promising properties as a high breakdown field, high carrier mobility and high thermal conductivity. Indeed, diamond-based Schottky diodes, using $\mathrm{Zr}$ metal over oxygen-terminated diamond surfaces, showing power figure of merit of $244 \mathrm{MWcm}^{-2}$ have been recently reported. However, designing reliable diamond Schottky diodes (SBD) or diamond-MOS capacitors are still a technological challenge. Indeed, a lack of knowledge of the bandgap behavior in hydrogen/oxygen-terminated diamond surfaces contacting metal and oxide layers should be first understood to take advantage of the outstanding properties of diamond in the electronic power devices engineering.

To pursue this objective, Scanning Transmission Microscopy (STEM)-based techniques as High Angle Annular Dark Field (HAADF) and Electron Energy Loss Spectroscopy (EELS), joined with X-ray photoelectron spectroscopy (XPS) and cathodoluminescence $(\mathrm{CL})$, are used to analyse the diamond/oxide interfaces of MOSFETs and SBD structures.

The atomic surface configuration related to diamond $/ \mathrm{Al}_{2} \mathrm{O}_{3}$ interface bandgap levels joined to the ALD-grown oxide bandgap itself are reported. The effect of the Cherenkov and plasmon-related peaks on the $E_{g}$ determination will be evaluated.

A relationship between nanostructure and energy bandgap in oxide layer at a nanometer-scale will be presented showing the importance of such aspects in the design of either MOSFET or SBD diamond related devices. 


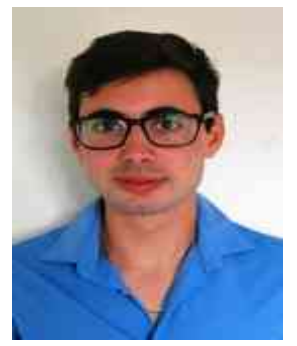

\title{
Electrodeposition strategies for antibacterial calcium phosphate coatings on titanium
}

\author{
C. Pierre (1), E. Vidal (2), G. Bertrand (1), E. Ruperez (2), C. Rey (1), \\ D. Rodriguez (2), C. Combes (1)
}

(1) CIRIMAT, Université de Toulouse, France, camille.pierre@ensiacet.fr

(2) Biomaterials, Biomechanics and Tissue Engineering Group, UPC, Spain, elia.vidal@upc.edu

Corresponding author: camille.pierre@ensiacet.fr

Keywords: ELECTRODEPOSITION, CALCIUM PHOSPHATE, ANTIBACTERIAL, COATING, TITANIUM IMPLANTS

Titanium and its alloys are the most used biomaterials for orthopedic and dental implants thanks to their good biocompatibility. Nevertheless, osseointegration of these implants is long to achieve and that is why surface treatments are applied to promote bone healing and growth. For that purpose, calcium phosphate coatings are commonly prepared [1]. Several coating processes can be used such as plasma spray, sol-gel, laser-deposition or electrodeposition. Among these techniques, electrodeposition is very attractive because it allows to produce thin coating on complex shapes and it is a low temperature process that permits to associate temperature-sensitive molecules of biological and/or therapeutic interest [2]. A second problem linked to the implantation is the bacterial colonization that may lead to implant loosening. The purpose of this study is to create a low temperature calcium phosphate bioactive coating on titanium to enhance osseointegration and also to associate an antibacterial agent with this layer to prevent post-operative infections [3], [4]. In this study, two strategies have been developed:

(5) Calcium phosphate electrodeposition was realized at constant potential and an antibacterial element (ie. $\mathrm{Ag}, \mathrm{Cu}, \ldots$ ) is then introduced by ionic exchange;

(6) Calcium phosphate and an antibiotic molecule were co-deposited by pulsed-electrodeposition.

The influence of the process parameters (current density/potential, $t_{\text {on }} / t_{\text {off }}$ ratios and electrolyte temperature) has been investigated. Scanning electron microscopy, X-ray diffraction, Raman and FTIR spectroscopies were used to characterize the coatings with and without the antibacterial agent. Moreover, adhesion between the substrate and the coating was also investigated. Preliminary antibacterial and drug release tests were also realized.

Coatings prepared by the two different methods were composed of mixed calcium phosphate phases. Changes in the process parameters produced different crystal morphologies. The addition of an antibacterial compound did not seem to influence the coating formation and its chemistry. All the studied coatings had good mechanical stability, in terms of adhesion and shear strength. In vitro antibacterial properties were also demonstrated against E. Coli and S. Aureus.

[1] R.A. Surmenev et al., Acta Biomater., vol. 10, no2, pp 557-579, 2014

[2] R.I. Asri et al., J. Mech. Behav. Biomed. Mater., vol. 57, pp 95-108, 2016

[3] D. Scharnweber et al., J. Mater. Med., vol. 18, no2, pp 391-397, 2007

[4] X. Lu et al., J.R. Soc. Interface, vol.8, no 57, pp 529-539, 2011

Acknowledgments: The authors thank the Midi-Pyrénées Region (BIOACTISURF project $\left.n^{\circ} 14054394\right)$, MAT201567183-R(MINECO/FEDER), AGAUR FI-DRG and the Cost Action TD1305 for supporting this research work. 


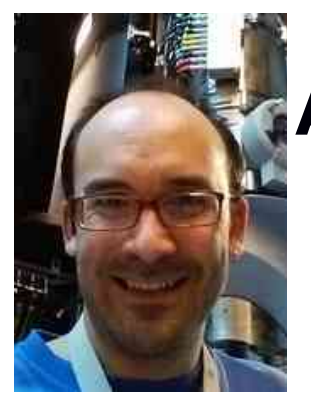

\title{
Aberration-Corrected Electron Microscopy of Advanced Functional Nanomaterials
}

\author{
C. Magén (1)
}

(1) Laboratorio de Microscopías Avanzadas (LMA), Instituto de Nanociencia de Aragón (INA) - ARAID, Universidad de Zaragoza, Spain, cmagend@unizar.es

\section{Corresponding author : cmagend@unizar.es}

Keywords : (SCANNING) TRANSMISSION ELECTRON MICROSCOPY, ABERRATION CORRECTION, NANOMAGNETISM, COMPLEX OXIDES, NANOSTRUCTURES

The fast emergence of Nanoscience during the last decades has been favoured by the development of new nanocharacterization tools with unprecedented resolution and sensitivity. In addition to the invention of scanning probe microscopy, traditionally considered the starting signal of Nanotechnology, the development of other types of microscopy techniques have contributed decisively to our understanding of the world at nanometer scale. In the field of Transmission Electron Microscopy (TEM), the most crucial milestone has been the development of aberration correctors. This new technology has offered scientist the possibility of atomically resolved characterization of structural, chemical and electronic properties of a wide range of advanced (nano)materials, with an undeniable impact on the development of novel materials in fields such as oxide thin films, semiconductor nanostructures, carbon based materials, magnetic nanostructures, nanoparticles, etc.

This lecture will review several applications of advanced TEM techniques that have been developed in the last years at the LMA, focusing on the work carried out in advanced materials for spintronic applications and the infrastructures available at the LMA to carry out these investigations. One of the subjects will the characterization of multiferroic oxide thin films, particularly the analysis of defects and domain walls that confer these materials unexpected physical properties, by the combination of atomic resolution imaging and spectroscopic techniques. Secondly, the potential of interferometric TEM techniques for the imaging of magnetization states at the nanometer scale will be demonstrated by illustrating the characterization of individual magnetic nanostructures and heterostructures grown by focused electron and ion beam techniques

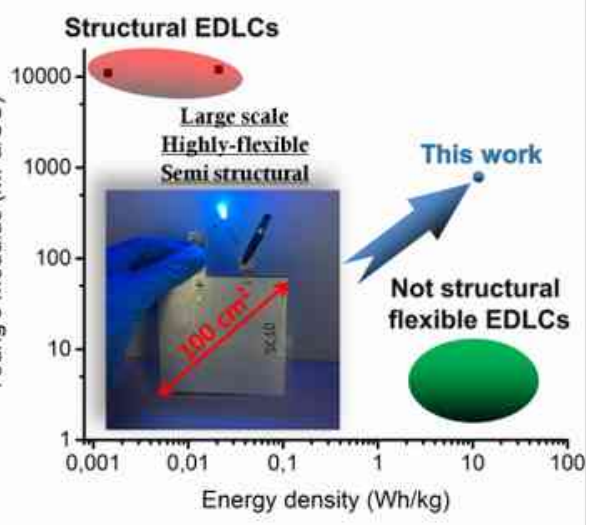
with different architectures. 


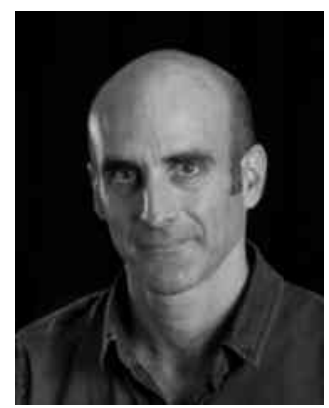

\title{
Flexoelectricity: from semiconductors to memory devices
}

\author{
G. Catalan $(1,2)$, J. Narvaez $(2,3)$, K. Cordero (2), U. Bhaskar $(2,4)$, \\ N. Domingo (2)
}

(1) ICREA, Barcelona, Spain

(2) ICN2 (Institut Catala de Nanociencia i Nanotecnologia), Barcelona, Spain

(3) Universidad de los Andes, Bogotá, Colombia

(4) Purdue University, Indiana, USA

\section{Corresponding author: gustau.catalan@icn2.cat}

Keywords : FLEXOELECTRICITY, FERROELECTRICITY, PIEZOELECTRICITY, MEMS, OXIDES

Flexoelectricity allows inducing polarization by bending (or by any other inhomogeneous deformation) in dielectrics of any symmetry, including centrosymmetric materials such as $\mathrm{SrTiO}_{3}$ and also ferroelectrics such as $\mathrm{BaTiO}_{3}$. While this has been traditionally exploited for making piezoelectric-like sensors using non-piezoelectric materials, there is a much wider variety of functional possibilities that have only recently started being explored. In my talk, I will cover three of them which our laboratory has been very directly involved:

1) Measuring flexoelectricity not on dielectric insulators but on semiconductors. In the latter, we have seen that the effective flexoelectric coefficient can be orders of magnitude larger than the flexoelectricity of insulators, and in addition it scales with thickness in such a way that it is a relevant effect even at the macroscale.

2) Using inverse flexoelectricity to make actuators that bend in response to a voltage (as opposed to sensors that generate a voltage in response to bending). These have been made in the form of MEMS cantilevers grown on silicon substrates, and are thus a technologically promising device concept.

3) Exploiting flexoelectricity not only to mechanically write ferroelectric domains, but also to mechanically read them, enabling the full voltage-free operation of a ferroelectric memory. 


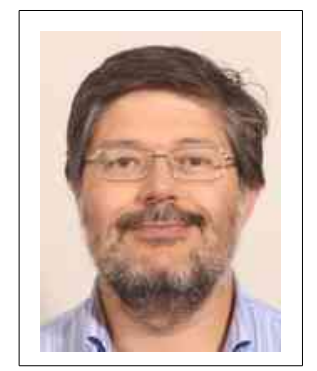

\title{
Characterizing magneto-thermal materials and processes at CICECO-UA INFRASTRUCTURES AND EXPERTISE
}

\author{
V. S Amaral (1), J. S. Amaral (2), N. J. O. Silva (3), A. Davarparnah \\ (4), F. Mohseni (5), T. Santos (6), M. J. Pereira (7)
}

CICECO and Physics Department, University of Aveiro, Portugal

(1) vamaral@ua.pt ; (2) jamaral@ua.pt ; (3) nunojoao@ua.pt ;

(4) amin.davarpanah@ua.pt ; (5) f.mohseni@ua.pt ;

(6) tiago.santos@ua.pt ; (7) mariasapereira@ua.pt

\section{Corresponding author : vamaral@ua.pt}

Keywords : MAGNETOMETRY; THERMAL CONDUCTIVITY; INFRARED THERMOMETRY; MAGNETOCALORIC

\begin{abstract}
Magnetic materials are in the front line to face challenges of energy conversion, savings and harvesting. The application of magnetocaloric materials into systems working in the vicinity of phase transitions provide the gains necessary to develop sustainable strategies for their innovative use. In the frame of thermal systems, mostly significant for cooling/heating, electrical energy supply processes and heat induction, materials optimization must also comprise their thermal conductivity, dynamic behavior and its dependence on the magnetic state of materials.
\end{abstract}

To face such a combined study towards optimization of magneto-thermal materials and processes, our group at CICECO-Aveiro Institute of Materials developed a new research infrastructure. Its main instruments are:

- Quantum Design MPMS3 SQUID-VSM Magnetometer (7 Tesla/ 1.8K-400K)

- HOT Disk TPS 2500 Thermal Properties Measurement system (thermal conductivity and specific heat) Transient Plane Source Method, $\left(0.005\right.$ to $1800 \mathrm{~W} / \mathrm{m} / \mathrm{K}$.) for solids or liquids, with bath $\left(-20^{\circ} \mathrm{C}\right.$ to $\left.180^{\circ} \mathrm{C}\right)$ and oven (up to $750^{\circ} \mathrm{C}$ ). A custom assembly for measurements under 1 Tesla magnetic field was also built.

- FLIR 5600 infrared thermography camera ( -20 up to $3000^{\circ} \mathrm{C}$ and $20 \mathrm{mK}$ resolution, up to $200 \mathrm{~Hz}$ frame rate in full resolution). Additional microscope (X5 lens, micrometer resolution) for local thermal mapping. A custom assembly for measurements under magnetic field cycling up to 1 Tesla was built.

- PARK XE-7 Atomic Force Microscope (AFM) with Scanning Thermal Probe Microscopy (SThM) probe and actuator (better than $100 \mathrm{~nm}$ resolution, with tip temperature up to $160^{\circ} \mathrm{C}$ ).

We present highlights in the context of developing materials, heat transfer, and measurement techniques.

CICECO-Aveiro Institute of Materials, POCI-01-0145-FEDER-007679 (FCT Ref. UID/CTM/50011/2013) is financed by national funds through FCT/MEC(PIDDAC) and co-financed by FEDER under the PT2020 Partnership Agreement. 


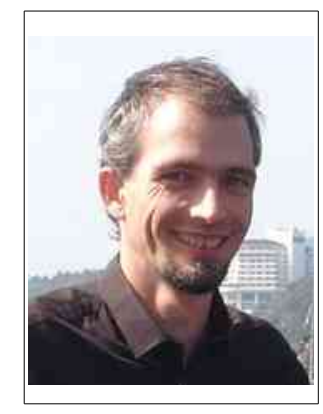

\title{
Photonic Crystals and Related Nanostructures for the Control of Light Trapping and Emission
}

\author{
C. Seassal, L. Lalouat, N.-V. Hoang, H. Ding, H.S. Nguyen, E. Drouard \\ Université de Lyon; Institut des Nanotechnologies de Lyon-INL, UMR CNRS 5270, \\ CNRS, Ecole Centrale de Lyon, Ecully F-69134, France
}

Corresponding author : christian.seassal@ec-lyon.fr

Keywords : NANOPHOTONICS, PHOTONIC CRYSTALS, LIGHT TRAPPING, WAVELENGTH CONVERSION, LIGHT EMISSION

Photonic crystals and related structures offer great potentialities for the next generation photovoltaic solar cells, light emitters and wavelength converters. In this communication, we will present advanced designs and strategies to carefully control light-matter interaction with advanced photonic nanostructures. Such control is based on photonic crystals and metastructures including active media and enabling a tight control of dispersion characteristics [1-2]. We will also discuss on the compromise between perfectly ordered and perturbated nanopatterns [3-4].

Theoretical predictions and experimental results will be presented as illustrations. We will discuss on the integration of photonic nanopatterns in thin film silicon solar cells, with a view to optimize their conversion efficiency. We will also present approaches and results related to light-emitting and wavelength conversion photonic structures using various types of active media.

[1] J. Marques-Hueso, R. Peretti, R. Abargues, B. S. Richards, C. Seassal, J. P. Martínez-Pastor, "Photonic CrystalDriven Spectral Concentration for Upconversion Photovoltaics," Advanced Optical Materials 3, pp568-574 (2014)

[2] R. Peretti, G. Gomard, L. Lalouat, C. Seassal, E. Drouard, "Absorption control in pseudodisordered photoniccrystal thin films," Phys. Rev. A 88, 053835 (2013)

[3] C. Seassal, L. Lalouat, H. Ding, E. Drouard, "Carefully mixing disorder and periodicity to optimize solar light trapping", SPIE Newsroom, Solar \& Alternative Energy, 14 July 2016

[4] L. Lalouat, H. Ding, B. Gonzalez-Acevedo, A. Harouri, R. Orobtchouk, V. Depauw, E. Drouard, C. Seassal, "Pseudo-disordered structures for light trapping improvement in mono-crystalline Si thin-films", Solar Energy Materials \& Solar Cells, 159, 649-656 (2016) 


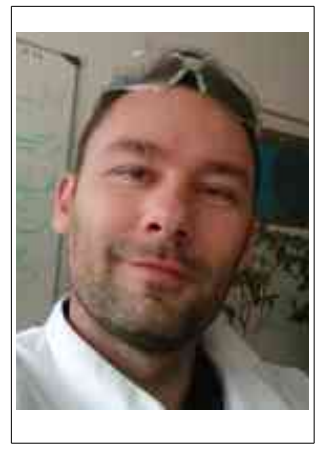

\title{
P3MT/VACNT/AI Nanocomposites Electrodes With High Capacitance For Supercapacitor
}

\author{
T. Vignal, ${ }^{\mathrm{a}, \mathrm{b}}$ L. Darchy, ${ }^{\mathrm{b}}$ A. Boisset, ${ }^{\mathrm{b}}$ H. Hauf, ${ }^{\mathrm{b}} \mathrm{J}^{\text {. Descarpentries, }}{ }^{\mathrm{b}} \mathbf{Q}$. \\ Mestre, ${ }^{\mathrm{c}}$ M. Pinault, ${ }^{\mathrm{c}}$ M. Mayne-L'Hermite, ${ }^{\mathrm{c}}$ P. Banet, ${ }^{\mathrm{a}}$ P.H. Aubert ${ }^{\mathrm{a}}$ \\ a LPPI, EA 2528, 5 MAIL Gay Lussac, Université de Cergy-Pontoise, France \\ ${ }^{\circ}$ NAWATechnologies SA, 190 avenue Célestin Coq-ZI, ROUSSET, France \\ ' NIMBE, CEA, CNRS, Université Paris-Saclay, CEA Saclay, Gif-sur-Yvette, France
}

Corresponding author: pierre-henri.aubert@u-cergy.fr Keywords : POLY(3-METHYLTHIOPHENE), CARBON NANOTUBES, ELECTRODE MATERIALS,
SUPERCAPACITORS

Supercapacitors are desirable for applications requiring high power densities. Among the various types of supercapacitors, electrochemical ones based on electronically conducting polymers (ECP) as electrode material are particularly interesting because of their high capacitance (1). However, their energy densities and their electrochemical stability are still limited $(2,3)$. In order to improve the capacitance and the energy density of such pseudo-capacitive supercapacitors, our strategy consists in making nanocomposite electrodes of poly-3-methylthiophene (P3MT) in ionic liquid media. These depositions were made on the surface of nanostructured electrodes composed of very dense carpet of vertically aligned carbon nanotubes $\left(10^{11}-10^{12}\right.$ $\mathrm{CNT} / \mathrm{cm}^{2}$ ) on an aluminium collector (VACNT/Al). In this study, different electropolymerizations methods (cyclic voltammetry, galvanostatic, potentiostatic, pulsed methods $(3,4)$ ) were used to optimized the deposition and the storage properties of P3MT. Thus, nanocomposites with weight ratios of P3MT/(P3MT+CNT) ranging from 5 to $90 \%$ were obtained and characterized by electrochemistry (CV and EIS) and microscopy. The results show that conformal depositions of polymers were obtained. In the case of the best nanocomposites, the electrodes capacitance increase from $32 \mathrm{mF} / \mathrm{cm}^{2}$ to $1300 \mathrm{mF} / \mathrm{cm}^{2}$. Finally, stability tests of electrodes and coin cells assembly were studied and their performances will be presented.

References:

[1] Mastragostino M. et al., Adv. Mater. 1996, 8, 331.

[2] Schnoor T. I.W. et al., Carbon 2013, 60, 229.

[3] Lagoutte S. et al., Electrochimica Acta 2014, 130, 754.

[4] Sharma R.K. et al., Electrochem. Commun. 2008, 10, 268. 


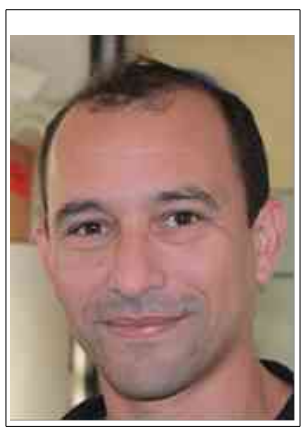

\title{
Biomimetic nanopore to design "smart" membranes
}

\author{
S. Balme (1)
}

(1) Institut Européen des Membranes, Université de Montpellier, France,

\section{Corresponding author : sebastien.balme@umontpellier.fr}

Keywords : SINGLE NANOPORE, MEMBRANE, BIOMIMETIC, SENSOR, SOFT MATTER

In the life science, it is well known that ionic bio-channels insure exchange and communication of living cells. Their properties in terms of ionic permeability, selectivity and response regarding the environment are exceptional. Unfortunately, the transfer of these properties to artificial set-up whose the mechanical strength is high enough to be useful in many different types of applications has not been made. The limitations of artificial nanopore membranes prepared by track-etched polymer sheets or transmission electron microscopy irradiation of thin silicon nitride film are the weak ionic selectivity and unresponsiveness against stimuli. Thus the main challenge consists of mimicking biological channels properties to design artificial nanopore membrane which is able to modulate their transport. To achieve this goal two strategies will be explored. The first one consists to a solid-state nanopore functionalized with more and less complex systems which permits to improve their properties. The second strategy is based in insertion of protein inside nanopore in order to obtain hybrid biological/artificial system. This strategy aims to combine the advantages of both solid-state nanopores (robustness, number, size and shape control) and biological channels (selectivity, precise structure)

In this talk, we will discuss on the different strategies to functionalize single track-etched nanopore using chemical grafting of (bio)macromolecule, self-assembly of poly-electrolytes or direction insertion of ion channel. Such functionalization permits to obtain nanopore with high ionic selectivity such as ionic-diode as well as design nanovalves which respond to ligand anchoring, $\mathrm{pH}$, light. We will show also the potentialities of functionalized nanopores for specific bio-sensor as well as osmotic energy. 


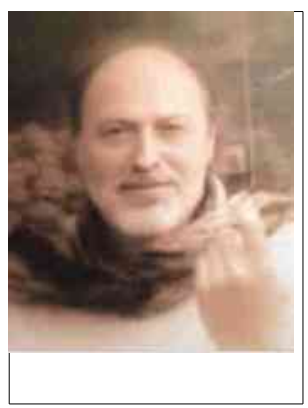

\title{
FE-AFE based functional oxide materials
}

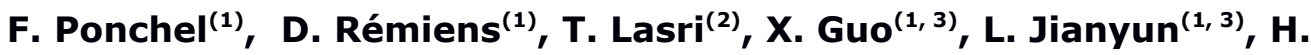 \\ Liuyang $^{(1,3)}$, J. Ge ${ }^{(1,3)}$, Y. Chen ${ }^{(3)}$, G. Wang ${ }^{(3)}$ \\ (1) IEMN - UVHC - UMR CNRS 8520 - Groupe MAMINA - Le Mont Houy \\ 59313, Valenciennes Cedex 9, France \\ Denis.Remiens@univ-valenciennes.fr \\ (2) IEMN - DHS - UMR CNRS 8520 - Groupe MITEC - Cité scientifique \\ Avenue Henri Poincaré, CS 60069 - 59652 Villeneuve d'Ascq Cedex, France \\ Tuami.Lasri@iemn.univ-lille1.fr \\ (3) Key laboratory of Inorganic Functional Materials and Devices \\ Shanghai Institute of Ceramics, Chinese Academy of Sciences (SICCAS) \\ 1295 Dingxi Road, Shanghai, 200050, China \\ genshuiwang@mail.sic.ac.cn
}

\section{Corresponding author : Denis.Remiens@univ-valenciennes.fr}

\author{
Keywords : ANTI FERROELECTRIC, STORAGE ENERGY, HIGH FREQUENCY TUNABILITY. LEAD FREE \\ PIEZOELECTRIC MATERIAL
}

In this talk we will present some results obtained in three directions, namely anti ferroelectric (AFE) thin films for energy storage applications, ferroelectric thin films for microwave applications and lead-free ferroelectric thin films which applications are potentially very large. Anti Ferro Electric (AFE) thin films for energy storage applications. The well known PbZrO3 (PZ) AFE material is deposited by rf magnetron sputtering on silicon substrate. More precisely, highly (001)-oriented pure PZ films and Sn-substituted PZ films are deposited on (001)-LaNiO3 buffered $\mathrm{SiO} / \mathrm{Si}$ substrates. Different Sn-substituted $\mathrm{PbZrO3}$ films (PbZr1-xSnxO3, $\mathrm{x}=0 \%, 3 \%, 5 \%, 10 \%$ ) with orthorhombic anti-ferroelectric phase are fabricated. The effects of Sn substitution on the structure and energy performance have been investigated in details. In another topic research, the dielectric properties (relative permittivity and losses) of PZT, PST and BST films were measured up to $60 \mathrm{GHz}$ using coplanar waveguides (CPW). Based on the CPW scattering parameters measurement, the frequency dependence of the complex permittivity has been determined thanks to a homemade numerical code based on finite elements. Even at $60 \mathrm{GHz}$ a large tunability of $47 \%, 30 \%$ and $60 \%$ has been measured for PZT, PST and BST respectively. Lead-based piezoelectric materials are well known for their excellent piezoelectric properties. However, due to the effects of lead toxicity, since recently it is desired to reduce lead-based materials usage in electronic devices. Therefore, lead-free materials have gained much interest in the microelectronic industry. In this context we have been working on Lead-free Bi0.5Na0.5TiO3 (BNT) piezoelectric thin films. BNT films were deposited on $\mathrm{Pt} / \mathrm{TiOx} / \mathrm{SiO} 2 / \mathrm{Si}$ substrates by sputtering. a piezoelectric coefficient (d33effmax) of $80 \mathrm{pm} / \mathrm{V}$ was obtained. BNT is regarded as an interesting alternative to PZT for MEMS application. 


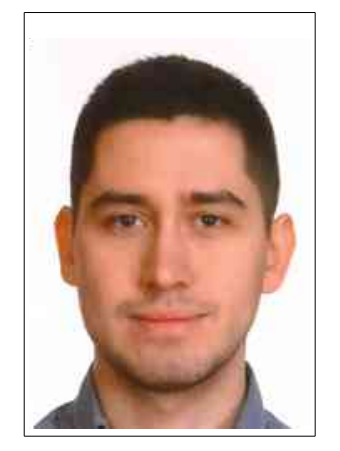

\title{
Energy Harvesting Materials Based on Carbon Nanotube Fibre for Tough Electronics
}

\author{
A. Monreal-Bernal, Juan J. Vilatela \\ IMDEA Materials Institute, Eric Kandel 2, Getafe 28906, Spain \\ Corresponding author : alfonso.monreal@imdea.org
}

Keywords : CARBON NANOTUBE FIBRE, ZINC OXIDE, TOUGH ELECTRONICS, SCHOTTKY BARRIER, PHOTOCONDUCTIVITY

Nanocarbons are very popular materials to interface with semiconductors. They combine extraordinary mechanical properties, high thermal stability, thermal conductivity and more importantly, very high carrier mobility. They have been shown to improve performance of (opto)electronic devices including solar cells, photoelectrochemical cells, and other applications involving interfacial charge transfer processes. A porous network of CNTs can act as a large-area scaffold for the semiconductor and be used as current collector to harvest carriers generated in the semiconductor by photovoltaic, photochemical and piezoelectric processes.

In the quest for making robust, flexible large-area devices based on nanocarbon/semiconductor hybrids (and other semiconductors) challenges remain in terms of the quality of nanocarbon/semiconductor junction that can be produced using simple large-area processes, and the mechanical robustness of these hybrid materials.

In this work we present a study on the structure and electronic properties of $10 \mathrm{~cm}^{2}$ scale $\mathrm{ZnO} / \mathrm{CNT}$ fiber materials. The carbon nanotube fibers (CNTf) combine a high surface area with bulk tensile strength, toughness and in-plane conductivities superior to steel and much greater than those of conventional vacuum-filtered CNT/graphene membranes. They are therefore ideal electrodes/current collectors to be combined with semiconductors, not only to produce new tough and efficient devices, but also as a test system to study lowdimensional properties of CNT/semiconductor junctions on a macroscopic scale. With these objectives in mind, this work presents a detailed characterisation of the electronic properties of bulk Schottky barrier heterojunctions between $\mathrm{CNTf}$ and $\mathrm{ZnO}$, from which various parameters of interest are extracted, including junction energy levels, dopant concentration, ideality factor and interfacial resistance. The hybrid material is also shown to be highly piezoresistive and piezoelectric, and as a demonstration of interfacial charge transfer we show piezoelectric energy harvesting. 


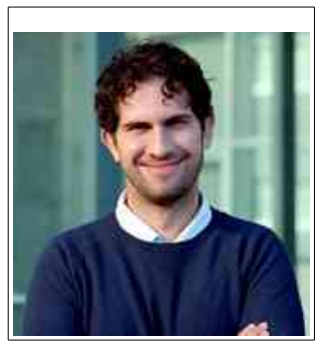

\title{
Epitaxial growth of nanostructured functional oxide thin-films by solution chemistry
}

\author{
José M. Vila-Fungueiriño (1), A. Gómez (2), R. Moalla (3), G. Saint- \\ Girons (3), C. Magén (4), J. Gázquez (2), R. Bachelet (3), M. Gich (2), \\ F. Rivadulla (5), A. Carretero-Genevrier (1)
}

(1) Institut d'Électronique et des Systèmes (IES), UMR 5214, Bâtiment 5, 860 rue Saint Priest, 34090 Montpellier, France

(2) Institut de Ciència de Materials de Barcelona (ICMAB), Consejo Superior de Investigaciones Científicas (CSIC), Campus UAB 08193 Bellaterra, Spain

(3) Institut des Nanotechnologies de Lyon (INL) UMR 5270, 36 avenue Guy de Collongue, 69134 Ecully, France

(4) Departamento de Física de la Materia Condensada, Universidad de Zaragoza, Zaragoza, Spain

(5) Centro de Investigación en Química Biolóxica e Materiais Moleculares (CIQUS), Universidade de Santiago de Compostela, 15782 Santiago de Compostela, Spain

jose-manuel.vila@ies.univ-montp2.fr

Keywords: EPITAXIAL THIN FILMS, OXIDES, POLYLER ASSISTED DEPOSITION

The variety of structures and properties provided by oxides offers an important route for the development of new devices integrated on different substrates such as silicon. At the interface of thin films and nanostructures the physical properties can strongly differ from bulk state due to the low dimensionality conditions imposed. In this regard, the control of crystallization mechanism at the nanoscale provided by the chemical solution methods is an affordable alternative to physical deposition techniques. However, the integration of functional oxides on silicon need to be further developed due to the dissimilarities on these materials, i.e. chemical reactivity, structural parameters, and thermal stability.

This work describes the synthesis of high quality epitaxial thin films and heterostructures of different functional oxides by Chemical Solution Deposition (CSD). In combination with Molecular Beam Epitaxy (MBE) these oxides can be epitaxially integrated in Silicon. In particular, complex oxide such as perovskites nanostructured thin films are synthetized by using a CSD method called Polymer Assisted Deposition (PAD) [1,2] supported with the controlled epitaxial growth of $\mathrm{SrTiO}_{3}$ (STO) buffer layer on $\mathrm{Si}$ [3]. By this route, $\mathrm{La}_{0.7} \mathrm{Sr}_{0.3} \mathrm{MnO}_{3}$ (LSMO) ultrathin films with abrupt interfaces and nanopillared $\mathrm{BaTiO}_{3}$ (BTO) on LSMO with good functionalities can be obtained exhibiting a great technological potential. The complementary of physical and chemical deposition techniques may stablish the basis for the development of low cost functional devices compatible with standard microfabrication technologies.

[1] Q. X. Jia et al. Nature Materials 3, 529 (2004).

[2] J. M. Vila-Fungueiriño et al. ACS Appl. Mat. Interfaces 7, 5410 (2015).

[3] J. M. Vila-Fungueiriño et al. Front. Phys. 3, 38 (2015) 


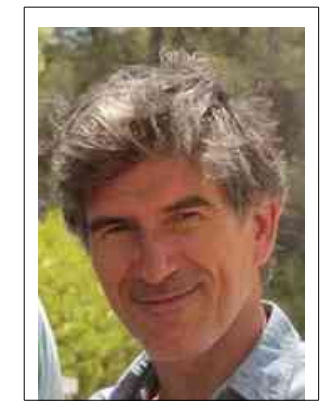

\title{
Confinement of organic dyes inside carbon nanotubes
}

\author{
A. Salvati(1), A. Belhboub(1), Alvarez (1), R. Leparc (1), S. Rols \\ (6),P. Hermet(1),B. Jousselme(3), K. Suenaga (4), A. Rahmani (5) J- \\ L. Bantignies (1)
}

(1) Laboratoire Charles Coulomb, University of Montpellier, France,

(2) Institut Laue-Langevin, Grenoble, France,

(3) Laboratoire d'Innovation en Chimie des Surfaces et Nanosciences (LICSEN), CEA Saclay, France

(4) Nanomaterials Research Institute, AIST, Tsukuba, Japan

(5) Laboratoire d'Etude des Mateŕiaux Avanceś et Applications,Universite 'Moulay Ismaïl, Morocco

(6) Institut Charles Gerhardt Montpellier,, University of Montpellier, France

\section{Jean-Louis Bantignies : jean-louis.bantignies@umontpellier.fr}

Keywords : ENCAPSULATION, CONFINEMENT, NANOTUBE, VIBRATIONAL SPECTROCOPIES, DFT

Opto-electronic properties of single-walled carbon nanotubes can be significantly modified by chromophore confinement into their hollow core. This presentation deals with quaterthiophene derivatives encapsulated into nanotubes displaying different diameter distributions. We show that the supramolecular organizations of the confined chromophores depend on the nanocontainer size. The Raman radial breathing mode frequency is monitored by both the number of confined molecules into a nanotube section and the competition between dye/dye and dye/tube wall interactions. The confinement properties lead also to an exaltation of the infrared absorption response $^{1}$ in single-walled carbon nanotubes from dye molecule interactions due to a symmetry breaking, allowing us, thanks to the complementarity of DFT calculations and experimental IR investigations to study interactions between both subsystems. Significant electron transfer from the confined molecules to the nanotubes is also reported from Raman investigations. This charge transfer leads to an important enhancement of the photoluminescence intensity by a factor of nearly five depending on the tube diameter. In addition, close to the molecule resonance, the magnitude of the Raman G-band shifts is modified and the intensity loss is amplified, indicating a photo-induced electron transfer. Results are discussed in the frame of electron-phonon coupling. Thus, confinement species into nanotubes allow moving the Fermi level and consequently to monitor their opto-electronic properties.

\section{Reference}

1. A. Belhboub et al., J. phys. Chem. C (2016) 120, 28802-28807. 


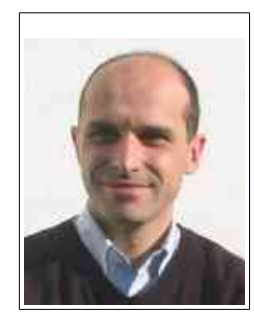

\title{
Electrostriction and giant permittivity of polymer nanocomposites
}

\author{
J. Yuan, A. Luna, A. Colin, C. Zakri, W. Nerin, P. Poulin
}

(1) Centre de Recherche Paul Pascal - CNRS, University of Bordeaux, 115 Avenue Schweitzer, 33600 Pessac, France

Corresponding author : poulin@crpp-bordeaux.cnrs.fr

Keywords : NANOCOMPOSITES, POLYMER, DIELECTRIC, ELECTROSTRICTION, ENERGY HARVESTING

The inclusion of conductive particles into insulating polymer matrices allows the synthesis of nanocomposites with tunable dielectric properties. In particular, giant permittivity is achieved when the conductive inclusions form near percolated networks. The permittivity of such nanocomposites strongly varies when the soft polymer matrix is deformed, giving rise to large electrostriction coefficients as needed in variable capacitors of energy harvesting devices.

Near percolated networks can easily be obtained with particles of anisotropic shape, such as carbon nanotubes, metal nanowires or graphene platelets. Because of their large aspect ratio, the particles exhibit a large excluded volume and a resultant low percolation threshold compared to spherical or quasi-spherical particles. The control of the spatial organization of the particles in the matrix is critical for the control of the material dielectric properties. We will present recent approaches to control the ordering of carbon nanotubes using emulsion templates to obtain enhanced dielectric permittivity and electrostriction coefficients [1]. We will also discuss differences or rod like particles from graphene platelets with giant anisotropy. The percolation behavior of graphene platelets has been recently predicted to be far more complicated than generally anticipated by excluded volume concepts [2]. Here, by characterizing the percolation transition in a liquid crystalline graphene based elastomer composite, we confirm experimentally that graphene flakes self-assemble into nematic liquid crystals (LCs) at concentrations below the percolation threshold [3]. We find that the competition of percolation and LC transition provides a new route towards high-permittivity materials. Near-percolated liquid crystalline graphene based composites display a giant permittivity along with a low loss tangent. The near percolated nanocomposites exhibit large permittivity variations in response to small strain deformations, giving rise to a giant electrostriction coefficients of about $M=-5 \times 10-14$ $\mathrm{m} 2 / \mathrm{V} 2$ at $100 \mathrm{~Hz}$. The present materials are promising for uses in variable capacitors of energy harvesters. Their implementation in actual electronic devices is currently investigated.

[1] Luna, A., Yuan, J., Neri, W., Zakri, C., Poulin, P. and Colin, A., (2015) Giant Permittivity Polymer Nanocomposites Obtained by Curing a Direct Emulsion. Langmuir 31: 12231-12239.

[2] Mathew, M.; Schilling, T.; Oettel, M., Phys. Rev. E 2012, 85 (6), 061407.

[3] Graphene Liquid Crystal Retarded Percolation for High Permittivity Materials , J. Yuan, A. Luna, W. Neri, C. Zakri, T. Schilling, A. Colin, P. Poulin , Nat. Comm. (2015) 6, 8700. 


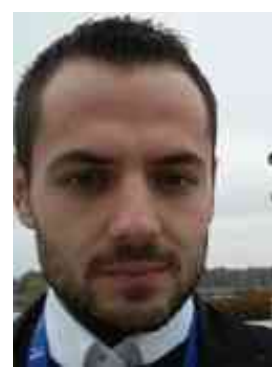

\title{
Structural Optimization and stability study of a yellow-to-transmissive Poly(ProDOT- carbazole) conjugated polymer
}

\author{
Clément Ernest (1), Xavier Sallenave (1), Pierre-Henri Aubert (1), \\ Frédéric Vidal (1), Claude Chevrot (1)
}

(1) Laboratoire de physicochimie des polymères et interfaces (LPPI, EA 2528), Université de Cergy-Pontoise, 5 mail Gay Lussac 95031 Cergy Pontoise Cedex, France

Corresponding author: Clément Ernest, clement.ernest@u-cergy.fr

\begin{abstract}
Keywords : CONDUCTING POLYMER, CONJUGATED POLYMER, ELECTROCHROMIC POLYMER
\end{abstract}
Most of pi-conjugated polymers are colorful in their neutral state, i.e. they show characteristic absorption in the visible part of the light spectrum (400-800nm). However, once p- doped (or oxidized), the absorbance spectrum of pi-conjugated polymers shifts to higher wavelengths values (Infra-red domain) and so, become colorless [1]. Among the accessible colors in the visible palette, getting polymers with yellow colors in the neutral state is more specific. Indeed, one absorption peak centered on $450 \mathrm{~nm}$ is needed to obtain this kind of yellow electrochromic material. Thus, we have synthesized, a conjugated polymer according to the procedure described in the literature as Suzuki polycondensation to yield a yellow-to transmissive switching electrochromic polymer $[1,2]$. This polymer is based on alterned propylenedioxythiophene (ProDOT) and 2,7-carbazole (Cbz) units as described in Figure 1. Since this polymer is soluble in common organic solvents, it could be deposited on various conductive substrates by spraycasting method on ITO glass. Thus, the optoelectronic properties have been characterized using UV/VIS spectroscopy, spectrocolorimetry, differential pulse voltammetry (colorimetric study while different potentials were applied), and spectroelectrochemistry. The study shows that this polymer displays vibrantly yellow-colored neutral and a transmissive light-grey oxidized state. These ProDOT-Cbz studies have allowed us to evidence some good colorimetric characteristics as $L^{*}$ values above 85 , $a^{*}$ values around -18 , and $b^{*}$ values around 80 (The color was assessed by utilizing the CIE $1976 \mathrm{~L}^{*} \mathrm{a}^{*} \mathrm{~b}^{*}$ Color Space), these values match with a bright yellow. Furthermore, this study allows us to highlight some issues, notably we have carefully studied the cyclability and aging of the ProDOTCbz polymer upon electrochemistry cycling. Modelling based on monomers and trimers with B3LYP and TD-B3LYP have also been carried out in order to be able to explain the different phenomena that have been observed during the optoelectronic characterization.
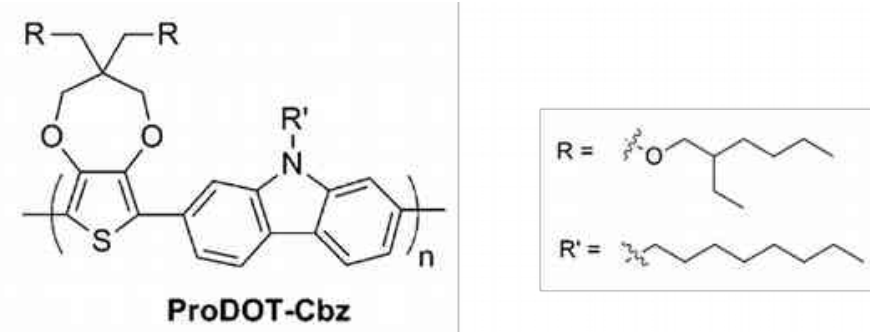

Figure1: ProDOT-Cbz polymer 


\section{Materials modelling}

\section{FROM AB-INITIO TO THERMODYNAMIC PROPERTIES}

\section{J. N. Gonçalves (1), A. S. Fenta (2, 3), C. O. Amorim (4), N. M. Fortunato (5), J. S. Amaral (6) and V. S Amaral_(7)}

(1) CICECO and Physics Department, University of Aveiro, Portugal, joaonsg@ua.pt

(2) CICECO and Physics Department, University of Aveiro, Portugal, fenta@ua.pt

(3) KU Leuven, Instituut voor Kern- en Stralingsfysica, Belgium, abel.silvafenta@kuleuven.be

(4) CICECO and Physics Department, University of Aveiro, Portugal, amorim5@ua.pt

(5) CICECO and Physics Department, University of Aveiro, Portugal, fortunato@ua.pt

(6) CICECO and Physics Department, University of Aveiro, Portugal, jamaral@ua.pt

(7) CICECO and Physics Department, University of Aveiro, Portugal,vamaral@ua.pt@ua.pt

\section{Corresponding author: joaonsg@ua.pt}

Keywords : MULTIFERROIC; MAGNETOCALORIC; GRAPHENE; FUNCTIONALIZED NANOPARTICLES

Computational materials modelling is a fundamental tool to perform structure research, materials properties prediction and design, and to assist the interpretation of experimental data. The multi-scale range of studies covers sub-atomic ab-initio electronic structure methods (Density Functional Theory-DFT) up to macroscopic thermodynamic properties.

Our group at Physics Department and CICECO is conducting research on developing and applying computational methods to materials science studies, covering a broad range of situations:

- Multiferroic materials (magnetic and dielectrics): use of DFT to study role of local charge and spin distribution on magnetoelectric coupling and hyperfine properties (magnetic field and electric field gradient)

- Magnetocaloric materials: DFT calculation of magnetic exchange interaction under strain, Monte-Carlo statistical physics methods and mean-field approaches to predict magnetocaloric materials performance in metals, alloys, and oxides

- Hydration layer and ad-atoms on graphene, their bonding, magnetic and hyperfine properties

- Local coordination of heavy ions adsorbed on functionalized nanoparticles

We will present some cases where the computational studies were closely related to current experimental work within the group and collaborations. 


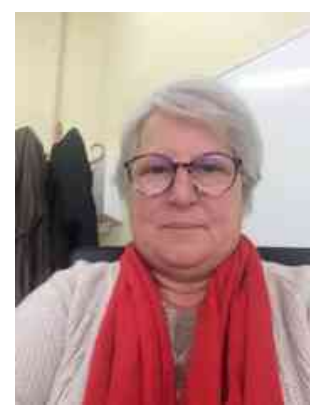

\title{
Advanced high temperature materials for space and energy applications
}

\author{
M. Balat-Pichelin \\ Procédés, Matériaux et Energie Solaire, PROMES-CNRS laboratory, Font-Romeu Odeillo, \\ France, marianne.balat@promes.cnrs.fr
}

Corresponding author : marianne.balat@promes.cnrs.fr

Keywords : HIGH TEMPERATURE, OXIDATION, EMISSIVITY, CERAMICS, REFRACTORY ALLOYS

The development of advanced materials - ceramics and refractory metals and alloys - that can withstand high temperatures is increasing as many applications can be encountered particularly in the space and energy fields. Concentrated solar energy is a useful tool to get very high temperatures in a few seconds in reactors under controlled atmospheres that can reproduce severe environments.

In this presentation, some examples will be given for space applications with the behavior of heat shields of spacecrafts during their atmospheric reentry such as the IXV one (Intermediate eXperimental Vehicle, ESA) which was successfully launched and recovered on February 2015, of the Solar Probe Plus mission (NASA) that will be launched in 2018, and the problem of space debris with the application of the French law LOS (Loi sur les Opérations Spatiales) mandatory by 2021 will be also presented.

In the field of energy, new ultra high temperature ceramics (UHTC) and coating layers on refractory alloys are under study to be implemented for the receivers of future solar power plants for electricity production in order to increase the temperature of the coolant (air at high pressure) and thus the efficiency.

The experimental reactors coupled to solar furnace facilities such as REHPTS and MESOX (Fig. 1) at the $6 \mathrm{~kW}$ solar furnace, and MEDIASE (Fig. 2) at the $1000 \mathrm{~kW}$ solar furnace will be presented together with recent original results on oxidation kinetics in air plasma conditions, behavior of materials in high vacuum, emissivity measurement at high temperature... according to the different environments encountered by the selected materials.

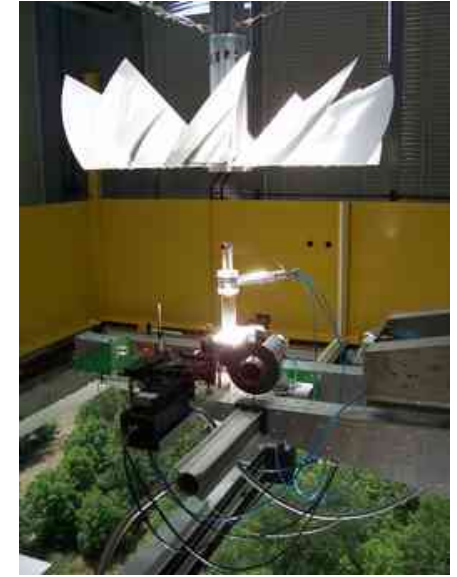

Fig. 1 : MESOX faclity at the $6 \mathrm{~kW}$ Odeillo solar furnace

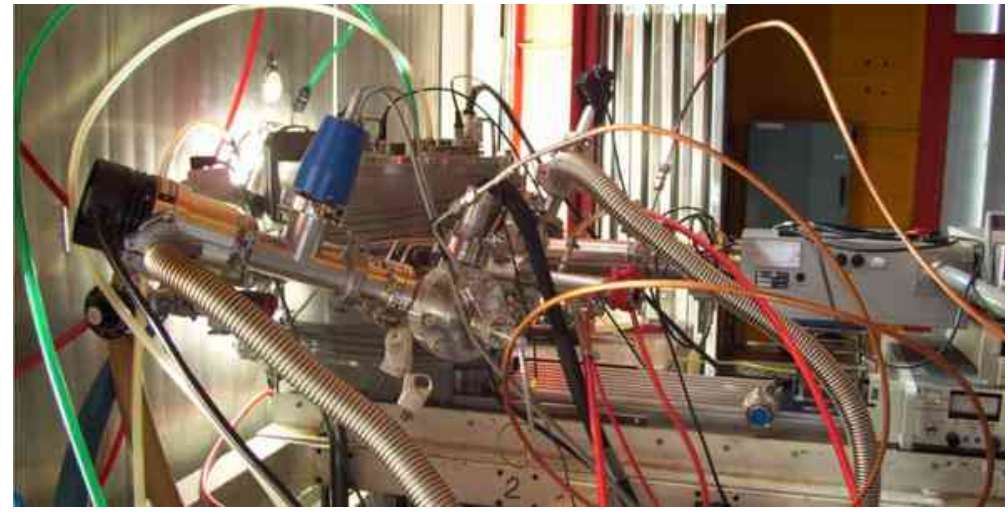

Fig. 2 : MEDIASE at the $1000 \mathrm{~kW}$ Odeillo solar furnace 


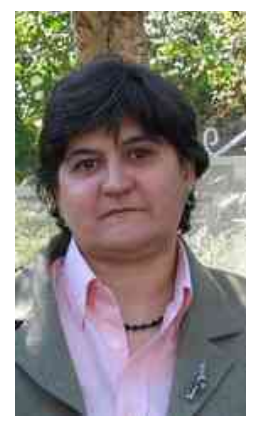

\section{ZnO, what is in?}

\section{Paloma Fernández}

Dept. Física de Materiales, Fac. Physics, University Complutense

Ciudad Universitaria, 28040 Madrid, Spain

\section{Corresponding author: $\underline{\operatorname{arana} @ u c m . e s}$}

Keywords : ZINC OXIDE, ZnO, II-VI COMPOUNDS, HISTORY OF MATERIALS, SEMICONDUCTORS, WIDE BAND GAP, EXCITON, LUMINESCENCE

II-VI compounds have been present almost from the early days of Human Civilization. Of course the main uses have changed along the time.

One of first references to such a compound can be found in Marco Polo's. In Book of the Marvels of the World, Chapter XXI, Concerning the city of Cobinan and the things that are made there. he refers to zinc oxide "...they also prepare both Tutia (a thing very good for the eyes) and Spodium; and I will tell you the process....". Where the Tutia is the Arabian name for some $\mathrm{ZnO}$ compounds and spodium is an ancient name for $\mathrm{ZnO}$ obtained by sublimation.

Much later, XIX century we find some references as that of von Döbereiner in Annalen der Physik und Physikalische Chemie, about the green luminescence of $\mathrm{ZnO}$, the so called Rinmann's Green, and at the end of the same century (1866), Sidot published an extensive study on the good properties of blende.

The advent of electronic devices and the consequent necessity to have homojunctions of good quality, prevented the massive use of compounds which, typically, cannot be prepared in both $\mathrm{p}$ and $\mathrm{n}$ type, due to the autocompensation phenomena. In this context III-V compounds won the match, until the last part of last century, where again the good properties such as wide band gap, high exciton energy or efficient luminescence were required.

A particular case in the frame of II- $\mathrm{VI}$ is $\mathrm{ZnO}$. What are the properties, which make this material so attractive? From phosphors and varistors to nanopiezotronics, we will give an overview of the main applications of this material and the phenomena behind. 


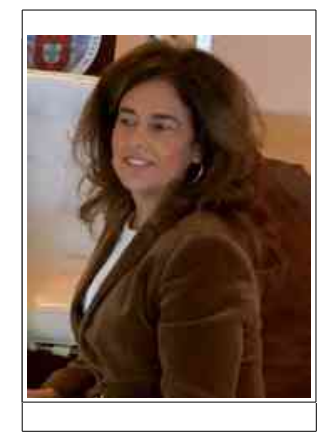

\title{
Biocompatible Piezoelectric Materials for Tissue Engineering
}

\author{
Paula M. Vilarinho (1)
}

Sebastian Zlotnik (1), Marisa Maltez da Costa (1), Nathalie Barroca( 1), M. Helena Fernandes (1), Sandra Vieira (2), M. Odete Cruz e Silva (2), Ana Colete Mauricio (3),

Brian Rodriguez (4)

\begin{abstract}
(1) Department of Materials and Ceramic Engineering, CICECO - Aveiro Materials Institute, University of Aveiro, Campus Santiago, 3810-193 Aveiro, Portugal

(2)Centre for Cell Biology, Health Sciences and Biology Departments, University of Aveiro, 3810-193 Aveiro, Portugal

(3) Clinicas Veterinárias, Instituto de Ciências Biomédicas Abel Salazar, Universidade do Porto, Porto, Portugal

(4) School of Physics and Conway Institute of Biomolecular and Biomedical Research, University College

Dublin, Dublin, Ireland
\end{abstract}

Paula M. Vilarinho; paula.vilarinho@ua.pt

Keywords : PIEZOELECTRICS, BIOMATERIALS, TISSUE GROWTH, BONE GROWTH

This talk is about an alternative approach to the development of the next generation of osteoinductive materials that can repair the body in-situ whilst permitting mobilization. The approach uses piezoelectric biocompatible materials.

The annual number of new bone fractures in the EU will rise from 3.5 million in 2010 to 4.5 million in 2025, corresponding to an increase of $28 \%$ [1]. Factures comprise hip, vertebral, forearm and others. Delayed fracture healing and nonunion occurs in up to $5-10 \%$ of all fractures [2]. Diseases such as arthritis, osteoporosis, tumours, and trauma may originate defects in the skeleton demanding a surgical procedure to replace or restore the lost bone. Although the comprehension of bone growth and fracture healing is presently very well advanced, efficacious bone treatments are still timely and of paramount importance.

Piezoelectrics are materials that can create electricity when subjected to a mechanical stress and reversely, generating a strain by the application of an electric field. Piezoelectrics find a wide range of applications as sensors, actuators and motors, in the automobile, aeronautics, computer, military, consumers and medical industry. The major medical applications of piezoelectrics include ex-vivo imaging; in-vivo tissue growth applications are seldom, if any. Starting from the relatively well known role of electrical stimulation on living tissues and assuming that in-vivo endogenous electric potentials can control cell functions as growth, migration and mitosis rate, in our work we are exploiting the usage of piezoelectrics as smart platforms for biological communication targeted for tissue growth. Our current results demonstrate the effect of polarization of biocompatible piezoelectrics (oxides and polymers) on protein adsorption and cells adhesion viability and proliferation.

[1] International Osteoporosis Foundation (IOF), Facts and Statistics, 2017.

[2] Bone healing in 2016, John A. Buza, III and Thomas Einhorn, Clin Cases Miner Bone Metab., 13 (2), 101 - 105, 2016, doi: 10.11138/ccmbm/2016.13.2.101 


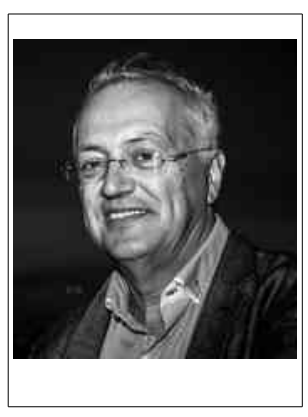

\title{
Bottom-up approach to epitaxial functional oxide nanostructures and nanocomposite thin films
}

\author{
X. Obradors, T. Puig, M. Coll, J. Gázquez, A. Palau, S. Ricart, N. \\ Mestres, A. Queraltó, P. Cayado, R. Guzmán, Z. Li, J. C. González, B. \\ Mundet, J. Jareño, L. Soler, C. Pop, B. Villarejo, N. F. Pino, N. \\ Chamorro, P. Machado, J. Banchewski, M. Tristany, A. Pérez del Pino, \\ E. Bartolomé
}

Institut de Ciència de Materials de Barcelona-CSIC, Campus UAB, 08193 Bellaterra, Catalonia, Spain

Corresponding author : xavier.obradors@icmab.es

Keywords : THIN FILMS, CHEMICAL SOLUTION DEPOSITION, SUPERCONDUCTORS, EPITAXY, FERROMAGNETISM

Complex oxides are a large arena of functional materials where quantum effects are becoming the main source of unique properties and functionalities. To fully exploit these novel opportunities a deep understanding of the growth mechanisms of ultrathin films, nanostructures and nanocomposites is required, as well as a detailed comprehension of atomic scale structure and its correlation with electronic states and functionalities.

Generation of large area arrays of self-organized oxide nanostructures (nanodots, nanowires) and large area thin and ultrathin films and nanocomposites provides unique opportunities for the development of novel functionalities with a wide range of potential applications (superconducting, electronic, magnetic, ferroelectrics, photovoltaics, resistive switching, etc.). Bottom-up approach based on chemical solution deposition (CSD) offers a high throughput (Ink Jet Printing) and cost-effective route for the generation of complex oxide thin films, multilayers and nanocomposite films while Atomic Layer Deposition (ALD) is very effective in modifying the interfacial properties or to grow ultrathin films at low temperatures.

In this talk I will review recent developments in the understanding of the growth mechanisms of epitaxial oxides derived from chemical solutions when Conventional Thermal Annealing (CTA), Rapid Thermal Annealing (RTA), Pulsed Laser Annealing (PLA) or Transient Liquid Assisted Growth (TLAG) are used. I will also show that CSD and ALD can be combined to prepare oxide multilayers with modified functionalities. The systems investigated include the ionic conductor Ce1-xGdxO2, ferromagnetic-metallic perovskites (La1-xSrxMnO3), perovskites with metalinsulator transitions (RENiO3), ferroelectrics (BaTiO3), multiferroics (BiFeO3) or YBa2Cu3O7 - derived nanocomposite high temperature superconductors. Some outstanding properties of these complex oxides are found to be linked to the nanoscale strain and complex atomic defects deciphered by HRTEM and XMCD. I will stress that to fully develop the strong potential of bottom-up approaches to complex functional materials the growth mechanisms need to be fully disentangled to achieve control of the relevant properties. 


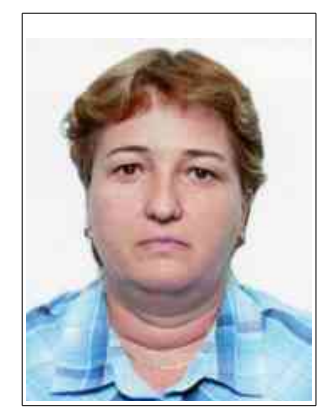

\title{
Lead-free ferroelectric and multiferroic systems from the Aurivillius family
}

\author{
A. Peláiz-Barranco (1), Y. González-Abreu (1), J.D.S. Guerra (2), P. \\ Saint-Grégoire (3), Y. Gagou (4), A. Rivas-Gutiérrez (1), J. Faloh- \\ Gandarilla (1), S. Díaz-Castañón (5).
}

(1) Facultad de Física-Instituto de Ciencia y Tecnología de Materiales, Universidad de La Habana. San Lázaro y L, Vedado. La Habana 10400, Cuba.

(2) Grupo de Ferroelétricos e Materiais Multifuncionais, Instituto de Física, Universidade Federal de Uberlândia. 38408-100, Uberlândia - MG, Brazil.

(3) MIPA Laboratory, Universities of Toulon and Nîmes, 30021 Nimes cedex 01, France.

(4) University of Picardie Jules Verne, LPMC, 80039 Amiens Cedex, France.

(5) División de Materiales Avanzados, Instituto Potosino de Investigación Científica San Luis Potosí, C.P. 78216, México.

\section{Corresponding author: pelaiz@fisica.uh.cu}

Keywords: FERROELECTRICS, MULTIFERROICS, CERAMICS

Over the last 20 years there has been an enormous effort in developing lead-free ferroelectric systems in order to obtain good dielectric, ferroelectric and piezoelectric properties than those the conventional ferroelectrics based on lead, such as PZT. The Ferroic Group Materials of the Physics Faculty, Havana University, Cuba, has been working since 1983 in the study of ferroelectric and piezoelectric materials, especially modified PZT and PT. An important group of lead-free ferroelectric materials belong to the Aurivillius family, compounds which are layered bismuth $\left[\mathrm{Bi}_{2} \mathrm{O}_{2}\right]^{2+}\left[\mathrm{A}_{n-1} \mathrm{~B}_{n} \mathrm{O}_{3 n+1}\right]^{2-}$ (see Figure). $\mathrm{SrBi}_{2} \mathrm{Nb}_{2} \mathrm{O}_{9}$ is a member of this family where the divalent $\mathrm{Sr}^{2+}$ cation can be totally or partially replaced by other cations, most commonly $\mathrm{Ba}^{2+}$. A few years ago, we have begun to work on $\mathrm{Sr}_{1-x} \mathrm{Ba}_{\times} \mathrm{Bi}_{2} \mathrm{Nb}_{2} \mathrm{O}_{9}$ lead-free ferroelectric materials. The barium concentration dependence of the dielectric behavior has suggested a cation site mixing among atomic positions, which has been supported by the structural analysis. A transition from normal ferroelectric-paraelectric phase transition to a relaxor behavior has been

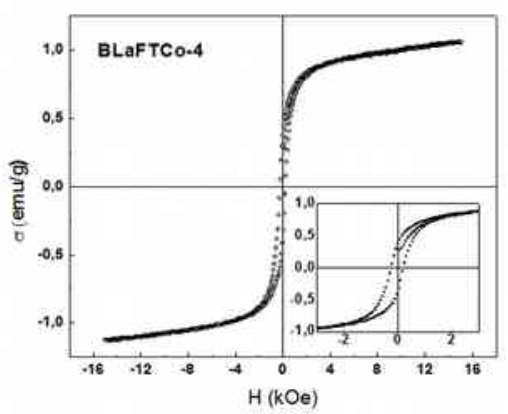
observed when the barium concentration 0 has increased. For the $\mathrm{Sr}_{0.70} \mathrm{Ba}_{0.30} \mathrm{Bi}_{2} \mathrm{Nb}_{2} \mathrm{O}_{9}$ composition has been obtained the better

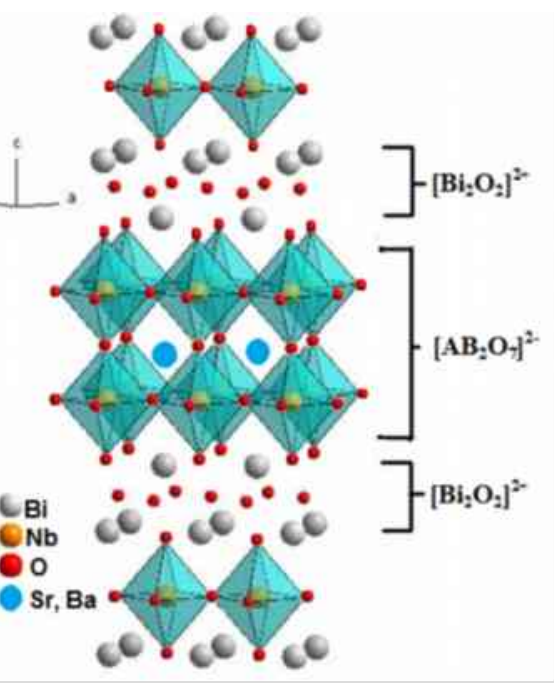
piezoelectric, pyroelectric and ferroelectric properties. Ferroelectric thin films have been also obtained for $\mathrm{Sr}_{0.70} \mathrm{Ba}_{0.30} \mathrm{Bi}_{2} \mathrm{Nb}_{2} \mathrm{O}_{9}$ and $\mathrm{Sr}_{0.15} \mathrm{Ba}_{0.85} \mathrm{Bi}_{2} \mathrm{Nb}_{2} \mathrm{O}_{9}$ compositions. On the other hand, the Aurivillius family systems are potential candidates as multiferroics by doping magnetic elements at the B-site. A magneto-electric four-layered structure $\left(\mathrm{Bi}_{5} \mathrm{FeTi}_{3} \mathrm{O}_{15}\right)$ can be obtained by inserting $\mathrm{BiFeO}{ }_{3}$ into $\mathrm{Bi}_{4} \mathrm{Ti}_{3} \mathrm{O}_{12}$, a classical three layers perovskite. $\mathrm{Bi}_{4.2} \mathrm{Ln}_{0.8} \mathrm{Fe}_{0.5} \mathrm{Co}_{0.5} \mathrm{Ti}_{3} \mathrm{O}_{15}$ $\left(\mathrm{Ln}^{3+}=\mathrm{La}^{3+}, \mathrm{Pr}^{3+}, \mathrm{Nd}^{3+}\right)$ multiferroic ceramics have been studied. The $\mathrm{Ln}^{3+}$ elements have showed an important influence on the characteristic magnetic hysteresis. The presentation will show a general overview of our researches on lead-free ferroelectric and multiferroic systems from the Aurivillius family.

Figures : Crystal structure of Aurivillius type with $m=2$ (upper, right); magnetic hysteresis loop in a multiferroic Aurivillius type material (bottom, left). 


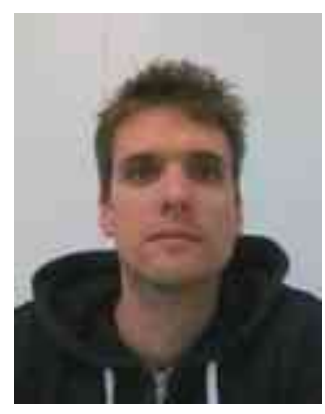

\title{
Advanced electrode materials for lithium and post-lithium batteries
}

\author{
R. Berthelot, N. Louvain, M. Sougrati, L. Stievano and L. Monconduit \\ Institut Charles Gerhardt de Montpellier (UMR5253) \\ Equipe "Agrégats Interfaces et Matériaux pour I'Energie" \\ Université de Montpellier, 2, place Bataillon CC1502 - 34095 Montpellier
}

Corresponding author : romain.berthelot@umontpellier.fr

Keywords : BATTERY ELECTRODE, POST-LITHIUM, BALL-MILLING, OPERANDO CHARACTERIZATION

In less than fifty years, lithium-ion batteries shifted from scientific discoveries to rapid industrial prototypes, before flooding the market of the electrochemical energy storage. This exceptional achievement escorted the huge explosion of electronical mobile tools such as cell phones, tablets or portable computers. Now lithium-ion batteries also equip hybrid or full electric vehicles and are also considered for grid storage. The lithium-ion technology is mature but there is still room for performance improvements. This can be done by protecting the surface of standardized electrode materials through chemical coating and hence prolonging the life of such batteries. This can also be done by investigating innovative electrode materials. In case of lithium becomes a strategical element, it is also important to investigate post-lithium electrochemical storage systems, such as sodium-ion or magnesiumbased batteries.In this presentation, we will summarize very recent results and ongoing research projects that we carry out at "Institut Charles Gerhardt de Montpellier". After a general introduction that will deal with the concept of rechargeable batteries and the electrode materials requirements, different examples of new materials for $\mathrm{Li}-, \mathrm{Na}-$, or Mg-ion batteries will be presented. It embraces the synthesis procedures that may strongly influence the final morphology of the active materials, and the optimization of the electrode formulation to enhance the electrochemical performance (specific capacity, lifetime, etc.) For some electrode materials that are investigated for a long time and already implemented in commercialized cells, the optimization of the electrochemical performance is still possible, for example by protecting the particle by a fluorinated shell that can help in reducing the solidelectrolyte interphase and thus accessing extra capacity. The understanding of the electrochemical process (ion insertion and de-insertion) is possible by performing operando characterizations, like X-ray diffraction, Mössbauer or X-ray absorption spectroscopies. Depending on the chemical nature of the electro-active materials, the electrochemical process might be a reversible intercalation of the cations or can undergo an alloying mechanism with new phases created. The deep investigation of the electrochemical mechanisms that occurs during the battery life may also help in evidencing the failure process. 


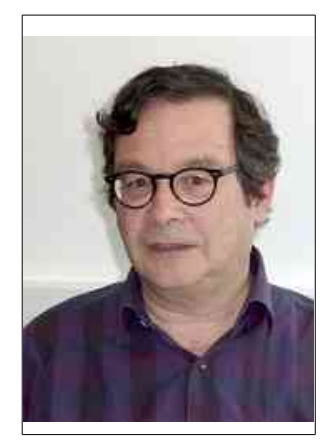

\title{
Nano-crystallization in decorative layers of ancient ceramics
}

\author{
Ph. Sciau, A. Pinto, M. Brunet, J. Groenen, C. Brouca-Cabarrecq \\ CEMES-CNRS, Université de Toulouse, France \\ Corresponding author : philippe.sciau@cemes.fr
}

Keywords : CULTURAL HERITAGE MATERIAL, ANCIENT CERAMIC,

Metallic lustre decorations of glazed ceramics, which appeared in Mesopotamia during the $9^{\text {th }}$ century AD, are certainly the most famous historical example of controlled nanotechnology for optical devices [1]. Yet, the use of optical properties of metallic particles is older. Actually, the tinting strength of metallic nano-crystal was used earlier for colouring glasses. It was shown that red glasses of Final Bronze Age (1200-1000 BC) from Frattesina di Rovigo in Italy were coloured thanks to crystalline particles of metallic copper dispersed in the surface layer of glassy matrix [2]. Many other examples can be found in literature showing that this glass staining process was widely used worldwide up to present times. Thus, the presence of both copper and cuprite particles was reported in Celtic enamels. Most of the Roman tesserae of red colour were obtained from a glass containing copper nano-crystal. These tesserae were produced massively during the Roman period thanks to a scale production of glass ingots. Outside Europe and Mediterranean basin, copper nanoparticles for colouring glasses and glazes were also massively used in Asia. For instance, the colouring of Japanese Satsuma glasses was obtained in this way. The blue-red Jun glazed porcelains made from Song to Qing Chinese Dynasties were manufactured using a similar process leading to the formation of copper nano-crystals in the red zones during firing. It is also the case for some Vietnamese porcelains and stonewares.

Beside metallic nano-crystals exploited for their optical properties, many other nanoscale crystals can be found in ancient ceramics and more specifically in their decorative or coating layers. These crystals can play a major role in the physical properties of these thin layers or merely be an indicator of the manufacturing process. These thin layers are formed during firing and result from physicochemical reactions among the diverse compounds of raw preparation. In general, the firing conditions are not suitable for obtaining large crystals and many of formed phases are in the form of nano or submicrometric crystals. Over time and in other places around the world, the variety of raw preparations and firing conditions used are so diverse that it is not conceivable to give here an exhaustive report. In this presentation, we will focus our attention on decorative layers of Greek and Roman potteries for which oxide nano-crystals play a key role in the optical and/or mechanical properties [3]. We will present also some glazed decorations of Chinese ceramics in which some rare and interesting phases for modern applications were found [4].

[1] Ph. Sciau, in The delivery of Nanoparticles, edited by A. A. Hashim (InTech, 2012), pp. 525.

[2] I. Angelini et al., J. Archaeol. Sci. 31 (8), 1175 (2004).

[3] Ph. Sciau. In Nanoscience and Cultural Heritage (Philippe Dillmman, Ludovic Bellot-Gurlet and Irène Nenner

(Ed.), Atlantis Press, 2016, ISBN 978-94-6239-197-0), pp. 41.

[4] C. Dejoie et al. (2014). Sci. Rep. 4, 4941 (DOI:10.1038/srep04941). 


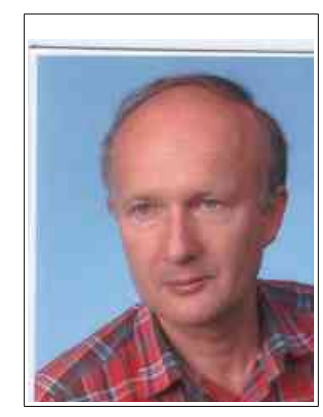

\title{
Long period modulated structures in trigonal double molybdates and tungstates
}

\author{
M. B. Zapart, w. Zapart \\ Institute of Physics,Technical University of Czestochowa, Poland \\ Corresponding author : zapart@wip.pcz.pl
}

Keywords : FERROELASTICS, MODULATED STRUCTURES, ORDER PARAMETER.

Double molybdates and tungstates with the general formula $\mathrm{MR}\left(\mathrm{XO}_{4}\right)_{2}(\mathrm{M}=$ an alkali metal $\mathrm{Li}-\mathrm{Cs}, \mathrm{Ag}$ or monovalent TI-ion, $\mathrm{R}=$ a rare earth element, $\mathrm{Bi}, \mathrm{In}, \mathrm{Sc}, \mathrm{Ga}, \mathrm{Al}, \mathrm{Fe}, \mathrm{Cr}, \mathrm{X}=\mathrm{Mo}, \mathrm{W}$ ) are well known in the literature. The structural diversity in these compounds reflects in a wide variety of physical properties. They may be considered as ferroelectric and ferroelastics, solid-state electrolytes, optical materials, phosphor and laser-host materials.

Some double molybdates and tungstates having a trigonal symmetry P-3m1 of the crystal structure exhibit interesting sequences of ferroelastic phase transitions. Also an existence of the incommensurate phases was reported in a few crystals belonging to this family, namely $\mathrm{KSc}\left(\mathrm{MoO}_{4}\right)_{2}, \mathrm{RbIn}\left(\mathrm{MoO}_{4}\right)_{2}, \mathrm{KSc}\left(\mathrm{WO}_{4}\right)_{2}$.

A group-theoretical analysis of possible transitions in the TDM/T compounds has shown that they lead either to monoclinic or triclinic systems and are induced by one of the two-dimensional irreducible representations of the space group, $\mathrm{T}_{5}$ or $\mathrm{T}_{6}$. The transition from the trigonal to monoclinic phases is improper one and is accompanied by a doubling of the unit cell along the threefold axis of the crystal, onset of spontaneous strain and nucleation of ferroelastic domains. However the above approach cannot account for the simultaneous existence of the ferroelastic and incommensurate phases in these crystals.

In order to explain such coexistence, the coupling of two order parameters $\eta$ and $\zeta$ was considered, responsible for doubling the size of the unit cell and the long period modulation of the crystal structure, respectively. Such an interaction of both parameters could lead to a variety of transitions, also to Dimmock's phases where both, long and short period modulated phases coexist. Experimental examples of such phases, derived from the observation of TDM / T crystals in polarized light and the electron paramagnetic resonance studies, were also provided. 


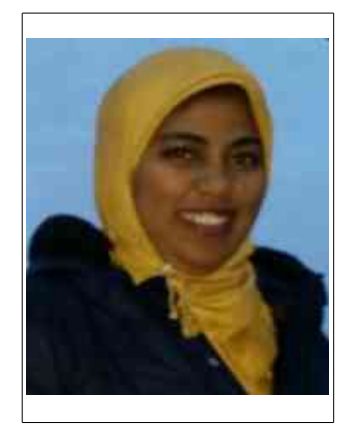

\title{
Electrocaloric measurements in lead- free materials
}

\author{
B. Asbani ${ }^{1,2}$ a), J.-L. Dellis ${ }^{1}$, Y. Gagou ${ }^{1}$, A. Lahmar ${ }^{1}$, M. Amjoud ${ }^{2}$, M. \\ Trček $^{3}$, Z. Kutnjak3, D. Mezzane ${ }^{2}$ and M. El Marssi' ${ }^{1}$ \\ 1 LPMC, Université de Picardie Jules Verne, 33 rue Saint-Leu, 80039 Amiens Cédex, \\ France \\ 2 LMCN, F.S.T.G. Université Cadi Ayyad, BP 549, Marrakech, Morocco \\ 3 Jozef Stefan Institute, Jamova cesta 39, 1000 Ljubljana, Slovenia \\ Corresponding author : bouchra.asbani@cnrs-imn.fr
}

Keywords : ELECTROCALORIC EFFECT, LEAD-FREE, PYROELECTRIC COEFFICIENT, Ba0.8Ca0.2TiO3 CERAMICS

\begin{abstract}
The electrocaloric (ECE) effect was investigated in lead-free doped $\mathrm{Ba} 0.8 \mathrm{Ca} 0.2 \mathrm{TiO} 3$ ceramics synthesized by a conventional sintering process. All analyzed ceramics exhibit tetragonal structure. The dielectric spectroscopy and calorimetry revealed that the Curie temperature decreases as a consequence of elements doping and that the ceramics exhibits a first order ferroelectric phase transition. Direct measurements using high resolution calorimetry were compared to the two indirect measurements using the Maxwell relationship. In a first well-known indirect method, P-E hysteresis loops were measured in a wide temperature range and pyroelectric coefficient and thus the electrocaloric responsivity were determined by derivation of $P(T, E)$ data. In second method the electrocaloric responsivity was determined by direct measurements of the pyroelectric coefficient and consequently the electrocaloric responsivity $\xi$ was determined by direct measurements of the pyroelectric currents under different applied electric fields [1]. Good agreement was obtained between different methods and large electrocaloric responsivity was found for some critical compositions around the dielectric maximum [2,3,4].
\end{abstract}

[1] B. Asbani, J-L. Dellis, Y. Gagou, H. Kaddoussi, A. Lahmar, M. Amjoud, D. Mezzane, Z. Kutnjak, M. El Marssi

EPL (Europhysics Letters) 111, 57008 (2015)

[2] B. Asbani, J.-L. Dellis, A. Lahmar, M. Courty, M. Amjoud, Y. Gagou, K. Djellab, D. Mezzane, Z. Kutnjak, M. EI Marssi, Applied Physics Letters 106, 042902 (2015)

[3] H. Kaddoussi, A. Lahmar, Y. Gagou, B. Asbani, J.-L. Dellis, G. Cordoyiannis, B. Allouche, H. Khemakhem, Z. Kutnjak, M. El Marssi, Journal of Alloys and Compounds, 667, 198 (2016)

[4] B Asbani, Y Gagou, J-L Dellis, A Lahmar, M Amjoud, D Mezzane, Z Kutnjak, Solid State Communications, 237238, P 49-54 (2016) 


\title{
Effect of Ce and La on the corrosion layer of new alloys Zn-RE
}

\author{
Khadoudj Guessoum (1), Delphine Veys-Renaux(2), Emmanuel Rocca(2), \\ Kamel Belhamel(1) \\ (1) Laboratoire des Matériaux Organiques, Département de Génie des Procédés, Faculté de Technologie, \\ Université de Béjaia, Béjaia 06000, Algeria \\ (2) Institut Jean Lamour-UMR CNRS 7198, Université de Lorraine-CNRS, BP 70239, Vandoeuvre-lès-Nancy \\ 54506, France
}

\section{Corresponding author : gueksabrina05@yahoo.fr}

Keywords : RARE EARTH, CORROSION, ALLOYS, CERIUM

New $\mathrm{Zn}-\mathrm{RE}_{1-5}$ w.\% alloys (RE=Ce and La) were synthesized by melting under controlled atmosphere and cast in plates. In these materials, rare earth metal are exclusively present in intermetallic phases homogeneously dispersed in the zinc matrix: $Z \mathrm{n}_{11} \mathrm{Ce}, \mathrm{Zn}_{13} \mathrm{La}$.

The electrochemical behavior of these new alloys was investigated in a reference corrosive medium. In parallel, the pure intermetallic phases $Z n_{11} C e$ and $Z n_{13}$ La were synthesized and their electrochemical influence was studied by voltametry and galvanic coupling.

From results of controlled precipitation experiments of cerium and zinc salts performed in carbonated medium, the presence of cerium in the corrosion layer and its protective character could be attributed to the formation of a mixed double lamellar zinc-cerium product. Therefore, addition to zinc of less than $2 \mathrm{wt} . \%$ of cerium or lanthanum allow to improve the corrosion resistance of zinc.

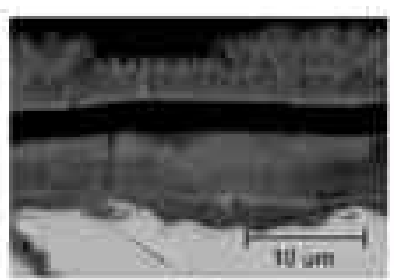

(a)

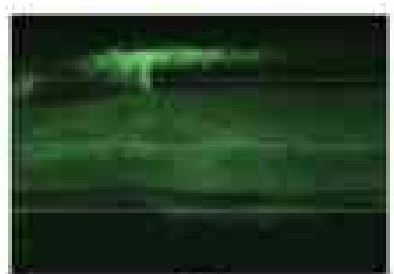

(b)

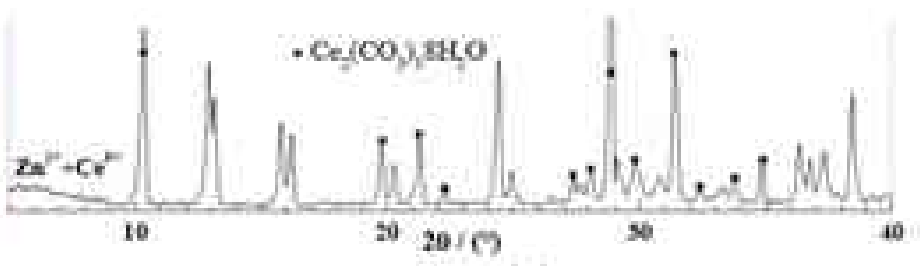

(c)

Cross-section corrosion layer of $\mathrm{Zn}-\mathrm{Ce}_{2}$ w.\% immersed 30 days in ASTM water: BSE image (a) and corresponding WDS X-Cartography of Ce (b); DRX pattern of a mixed double lamellar product (c) . 


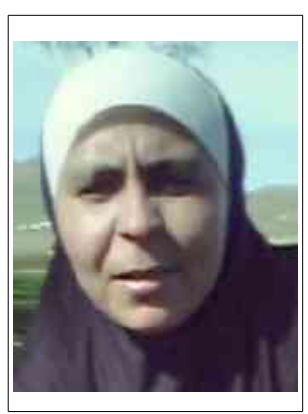

\section{Synthesis of $\mathrm{Cu}_{2} \mathrm{ZnS}_{3}$ Wurtzite by sol-gel process}

\section{INFLUENCE OF PREPARATION TEMPERATURE}

\section{Hamici (1) and P.Saint-Grégoire (2).}

(1) DAC-HR Laboratory, Sétif -1,University, Algeria

(2) MIPA Laboratory, Universities of Toulon and Nîmes, France

Corresponding author : hemissi_melia@yahoo.fr.

Keywords : CZT, X-RAY DIFFRACTION, MEB, SEMI-CONDUCTOR, WURZITE.

$\mathrm{Cu}_{2} \mathrm{ZnS}_{3}$ (CZS) is certainly one of the most promising materials for photovoltaics. It has a direct band gap that may be tuned between 1.4 and $1.6 \mathrm{eV}$, and a high absorption coefficient over $10^{4} \mathrm{~cm}^{-1}$. Moreover, the fact that it is composed of earth abundant and non-toxic constituents, and that its synthesis does not involve a polluting or energy consuming process, makes this compound an environment friendly one.

In the present study, the wurtzite CZS material has been prepared by a sol-gel route. The CZS samples have been characterized structurally by X-ray diffraction (XRD), morphologically by scanning electron microscopy (SEM) and optically using a UV-vis spectrophotometer. The compound appears to be more stable than the quaternary CZTS $\left.\left(\mathrm{Cu}_{2} \mathrm{ZnSnS}\right)_{4}\right)$, also considered promising for photovoltaics. SEM studies reveal that the morphology of the obtained materials - powders or films - depends strongly on the annealing temperature and crystallization process. The structure of films may include agglomerated nanocrystals or intricated fibers, among others (see figures). The study of optical absorption reveals a band gap around $1.55 \mathrm{eV}$, suitable for photovoltaic applications.
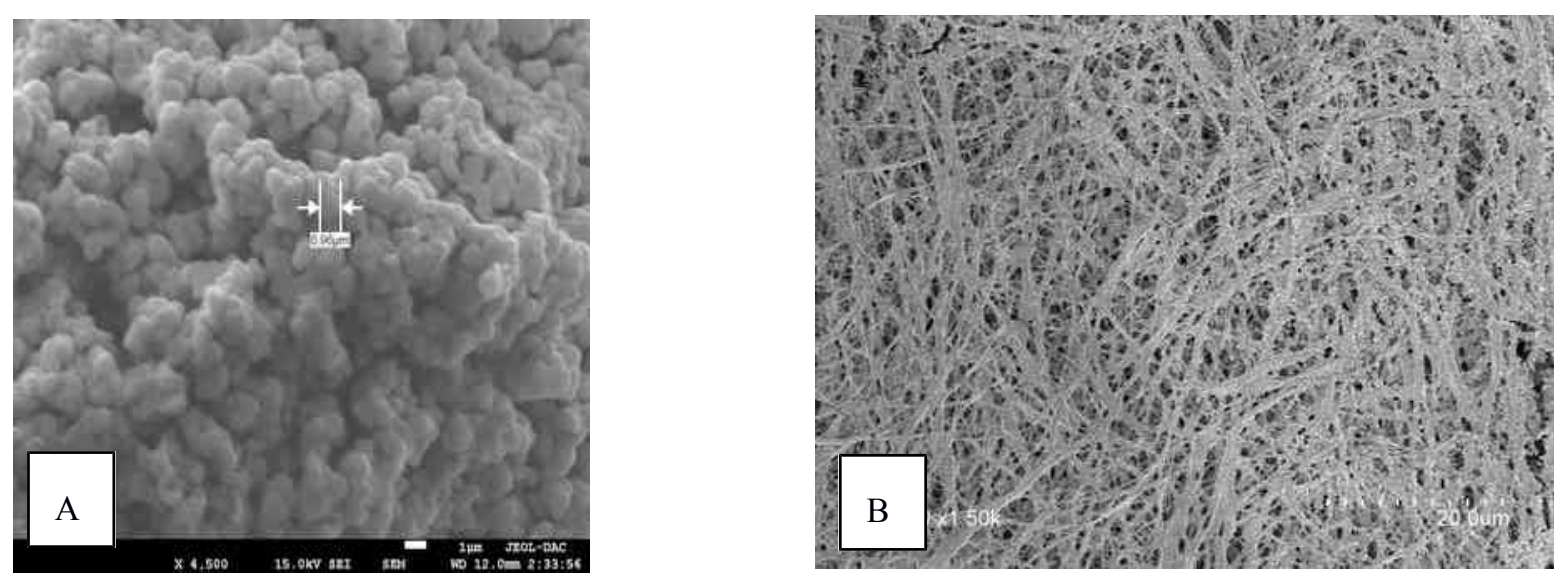

SEM Images of $\mathrm{Cu}_{2} \mathrm{ZnS}_{3}$ thin layer A) as-grown, and B) after a sharp heating at $400^{\circ} \mathrm{C}$ during drying 


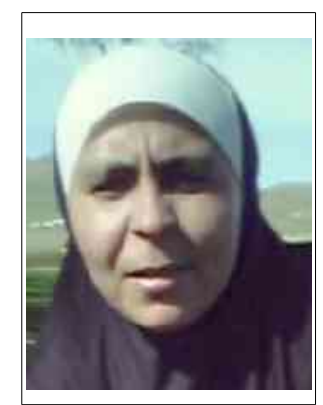

\section{Oxidation process of $\ln _{2} S_{3}$ crystalline powder}

\section{Hamici (1), L. Vaillant (2), and P. Saint-Grégoire (3)}

(1) DAC-HR Laboratory, Sétif -1,University, Algeria, hemissi_melia@yahoo.fr

(2) Enermat Division, Institute for Science \& Technology of Materials (IMRE), University of Havana, Zapata esg G, s/n, 10400 Cuba

(3) MIPA Laboratory, Toulon and Nimes Universities, France, pstgregoire@gmail.com

\section{Corresponding author: hemissi_melia@yahoo.fr}

Keywords : In2S3, In2O3, OXIDATION, PHOTOVOLTAICS, CHEMICAL BATH, THERMAL ANALYSIS

$\mathrm{In}_{2} \mathrm{~S}_{3}$ is a promising material that has been studied in the last years mainly in reason of its potential interest in solar cells as a CdS buffer layer substitute for fabricating Cd-free CIGS solar cells. $\ln _{2} S_{3}$ films of the crystalline $\beta$ form may be obtained by Chemical Bath Deposition (CBD), physical vapor deposition (PVD) and by spray pyrolysis.

In the literature the oxidation of $\ln _{2} S_{3}$ films was described for films obtained by CBD and PVD. Some of us showed that the oxidation process depends on the film microstructure : the temperature region in which the oxidation occurs is strongly dependent on the size of crystals in deposited films, and the temperature of annealing in air determines the composition of the solid solution.

A potential interest of the intermediate compositions is that the band gap varies as a function of composition and can be tailored to intermediate values between the band gap value for $\ln _{2} S_{3}$ and that for $\ln _{2} \mathrm{O}_{3}$, that should influence the efficiency of solar cells built with the corresponding buffer layer. However on the other hand, such nanostructured thin films are fragil with respect to heating or also to chemical attacks. Attempts to deposit p-type semiconducting materials $\mathrm{Cu}_{2} \mathrm{SnS}_{3}$ (CTS) and $\mathrm{Cu}_{2} Z n \mathrm{ZnS}_{4}$ (CZTS) on $\ln _{2} \mathrm{~S}_{3}$ thin films, with a penetration of the $p$ type semiconductors, are made difficult because of chemical instability of the $\ln _{2} S_{3}$ film in the corresponding baths.

This situation motivated us to investigate the possibility to obtain $\ln _{2} S_{3}$ films by Dr Blade technique, and to study carefully the behaviour of such films and constitutive crystalline powders, that have grains with a micrometric size as evidenced in the SEM, to be compared with results obtained with nanometric powders resulting from thin films as studied recently.

In this communication we present first the films obtained by Dr Blade, and then results of TGA that show weight losses in nitrogen that correspond to elimination of solvents, and thereafter weight losses in air, accompanying the substitution of sulphur by oxygen in the structure. This mechanism is confirmed by analyses performed by EDX and the obtained materials are also studied by X-ray diffraction (XRD). The variation of bandgap of the obtained materials of different compositions is deduced from UV-visible spectrometry data.

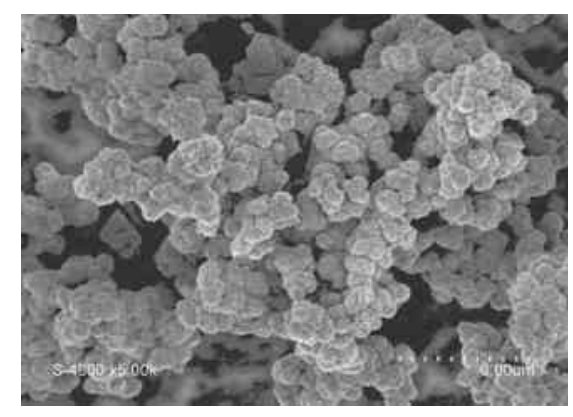

Figure 1: SEM micrograph of $\operatorname{In}_{2} \mathrm{~S}_{3}$ powder

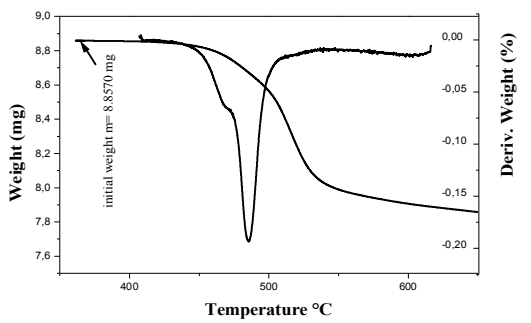

Figure 2: Weight loss versus temperature in air atmosphere (TGA measurement) 


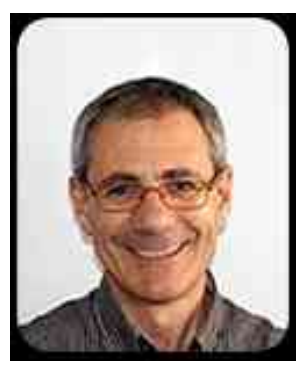

\title{
3D-FIB characterization of the martensitic transformation on shot peened metastable steels
}

\author{
G. Fargas, J.J. Roa, A. Mateo \\ CIEFMA - Departament de Ciència dels Materials i Enginyeria Metal·lúrgica, \\ EEBE-Universitat Politècnica de Catalunya, Barcelona
}

Corresponding author: antonio.manuel.mateo@upc.edu

Keywords: FOCUS ION BEAM (FIB), SHOT PEENING, METASTABLE STEELS, MARTENSITE

\begin{abstract}
Metastable austenitic stainless steels can be considered as TRIP (Transformation Induced Plasticity) steels because plastic deformation leads to transformation from austenite to martensite. On the other hand, during service life of a component manufactured with these steels, fatigue failure may occur. Therefore, shot peening could be used to increase their fatigue resistance. Despite numerous investigations have shown the beneficial effects of shot peening on austenitic stainless steels, scarce information exists related to metastable grades.

In the present work, the relationship between microstructural changes induced by shot peening and fatigue behavior of a commercial AISI $301 \mathrm{LN}$ (corresponding to standard EN 1.4318) metastable steel was studied. Two different steel conditions were selected: annealed (with fully austenitic microstructure) and cold rolled (with a biphasic microstructure composed by austenite and martensite). The deformed microstructure on the subsurface was analyzed on cross-section specimens through the shot peened region by means of 3D-FIB (Focus lon Beam) tomography collecting around 400 sequential images milled with a $\mathrm{Ga}+$ ion beam current.
\end{abstract}

Results pointed out that extensive plastic deformation and phase transformation developed in annealed specimens as a consequence of shot peening. However, the increase of roughness and the generation of microcracks led to a limited fatigue limit improvement. In contrast, shot peened cold rolled specimens exhibited enhanced fatigue limit. In the latter case, the main factor that determined the influence on the fatigue response was the distance from the injector, followed by the exit speed of the shots and the coverage factor. 


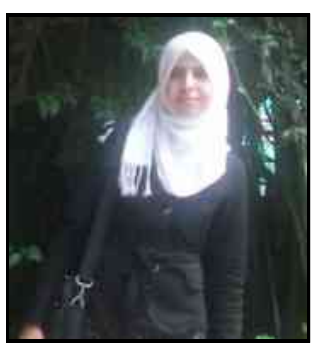

\section{Synthesis of Co doped Zno thin films by Sol-Gel}

\section{N. Lameche (1), M.Hemici (2)}

(1) Applied Optics Laboratory, University of Setif1-Algeria,norelhouda_l@yahoo.fr (2) Dosage, analysis and characterization Laboratory, University of Setif1-Algeria , hemissi_melia@yahoo.fr

\section{Corresponding author: norelhouda_1@yahoo.fr}

\section{Keywords : COBALT DOPED ZnO, DIP COATING, THIN FILMS, OPTICAL CONSTANTS}

In the present work, $\mathrm{ZnO}$ and $\mathrm{Co}: \mathrm{ZnO}$ thin_films with different percentage of Cobalt content were deposited by dip_coating technique. The sol has been prepared by reacting Zinc acetate and Cobalt (II) Nitrate in 2-propanol alcohol. The effect of Cobalt doping concentration on the structural, optical, morphological proprieties of $\mathrm{ZnO}$ thin_films was investigated. The Wurtzite structure was observed in all deposited films and the presence of Zinc, Oxygen and Cobalt was confirmed by using EDX analysis. The optical constants (Refraction index, absorption, extinction and dielectric constants) were found to depend on the Cobalt content. The band_gap energy decreased from 3.26 to $3.20 \mathrm{eV}$ with increasing Cobalt concentration. Cobalt effect modified the surface morphology of $\mathrm{ZnO}$ thin_films. RMS roughness and crystallite size decreased when Co doping increases from 0 to 8 at.\%.

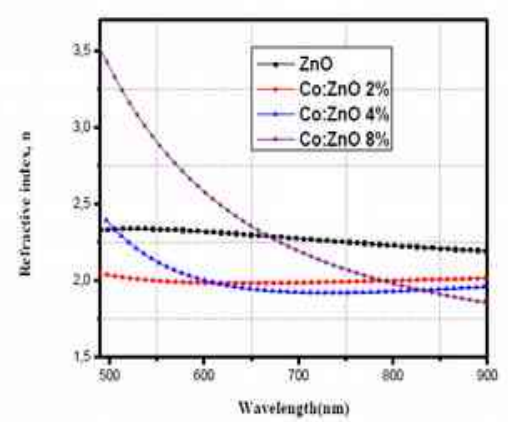

Fig.1: Spectral dependences of refractive index (n) of the undoped and Co-doped $\mathrm{ZnO}$ thin films

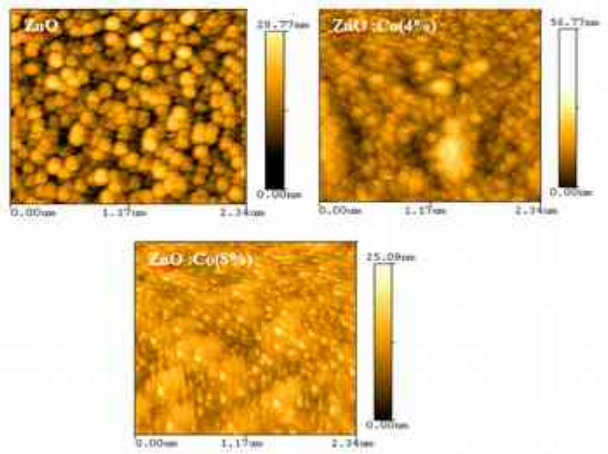

Fig. 2 : AFM images of undoped and Co-doped $\mathrm{ZnO}$ thin films 


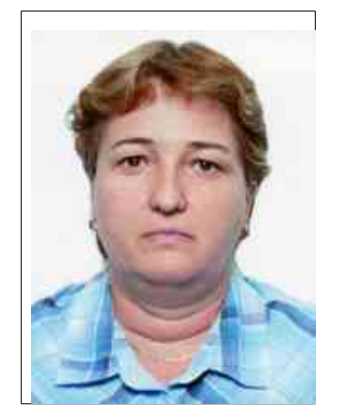

\title{
Ferroic Systems: The Cuban experience
}

\author{
A. Peláiz-Barranco, F. Calderón-Piñar, O. García-Zaldívar, Y. González- \\ Abreu, Y. Mendez-González, Y. García-Puente
}

Physics Faculty-Institute of Science and Technology of Materials, Havana University, San Lázaro y L, Vedado. La Habana 10400, Cuba.

Corresponding author: pelaiz@fisica.uh.cu

Keywords : FERROELECTRICS, ANTIFERROELECTRICS, MULTIFERROICS, CERAMICS

The Research's Group on "Ferroic Materials" of the Physics Facultỹlnstitute of Science and Technology of Materials, Havana University, Cuba, was founded in 1983 (named before "Ferroelectrics Group"). The first researches were realized for search of high efficiency of piezoelectric energy conversion and low dielectric loss for ultrasonic generation. Today, the main research topics are about ferroelectric, antiferroelectric and multiferroic systems. Ceramics systems of high quality have been obtained for several years. Thin films and composites have been also obtained. Structural, dielectric, piezoelectric, pyroelectric, ferroelectric and magnetic analyzes have been carried out in a wide variety of systems such as $\mathrm{PbTiO}_{3}, \mathrm{~Pb}(\mathrm{Ti}, \mathrm{Zr}) \mathrm{O}_{3}, \mathrm{~Pb}\left(\mathrm{Zn}_{1 / 3} \mathrm{Nb}_{2 / 3}\right)-\mathrm{PbTiO}_{3}-\mathrm{BaTiO}_{3}, \mathrm{SrBi}_{2} \mathrm{Nb}_{2} \mathrm{O}_{9}$, $\left(\mathrm{Bi}_{0.5} \mathrm{Na}_{0.5}\right) \mathrm{TiO}_{3}-\mathrm{BaTiO}_{3}, \mathrm{BiFeO}_{3}, \mathrm{BiFe}_{0.5} \mathrm{CO}_{0.5} \mathrm{Ti}_{3} \mathrm{O}_{15}$, and others, included several modifications of them. Ferroelectric phase transitions, relaxor behavior, dielectric relaxation and electrical conductivity, thermally stimulated processes and pyroelectricity, ferroelectric-antiferroelectric coexistence, ferroelectric-ferrimagnetic coexistence, electrocaloric effect and energy storage are some of the most important developed topics. The presentation will show a general overview of the group, the principal topics and results, the main scientific collaborations, etc. 


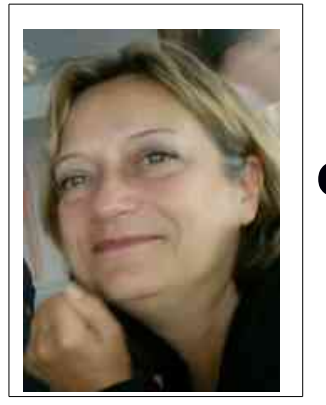

\title{
X-ray absorption spectroscopies in correlated oxides and advanced materials
}

\author{
A. Y. Ramos $(1,2)$, S. Grenier(1,2), A. Bailly $(1,2)$, Y. Joly $(1,2)$
}

(1) Univ. Grenoble Alpes, Inst NEEL, F-38000 Grenoble, France

(2) CNRS, Inst NEEL, F-38000 Grenoble, France

Corresponding author : aline.ramos@neel.cnrs.fr

Keywords : XAS, HERFD-XANES, REXS, OXIDE

We study the correlations between structural and electronic properties in a wide set of solid compounds ranging from 3D bulk materials, thin films at the 2D limit, down to 1D nanoparticles. Our common tools are related to $x$-ray absorption spectroscopy (XAS) and resonant $x$-ray scattering (REXS) with large applications in correlated oxides and developments of these technics and analysis tools.

XAS allows to probe the valence and structure of the coordination shells for a target chemical element. In the so called HERFD mode, the specific emission lines ( $K \alpha, K \beta 1,3, K \beta 2,5 .$.$) of the absorbing element are$ independently collected using crystal analyzer spectrometer. This significantly improves X-ray Absorption Near Edge Structure (XANES) features and the counting statistics, but also gives access to spin, redox and ligand sensitivity.

Surface-REXS couples of the capabilities of surface diffraction and resonant scattering for the investigations of electronic structure in ultrathin films and at surfaces.

Our measurements carried out at the French Collaborating Research Group beamlines at the ESRF, and the analysis is based on ab initio simulations in a mono-electronic approach using the advanced FDMNES code.

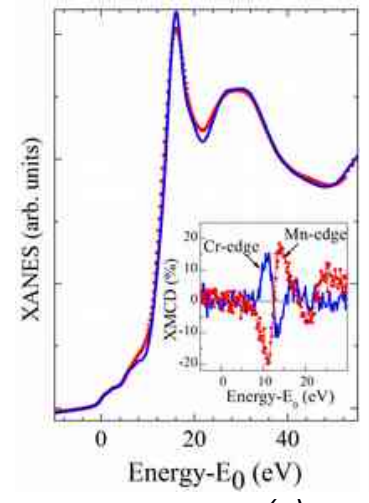

(a)

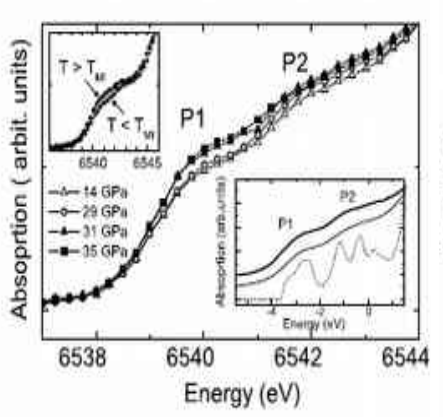

(b)

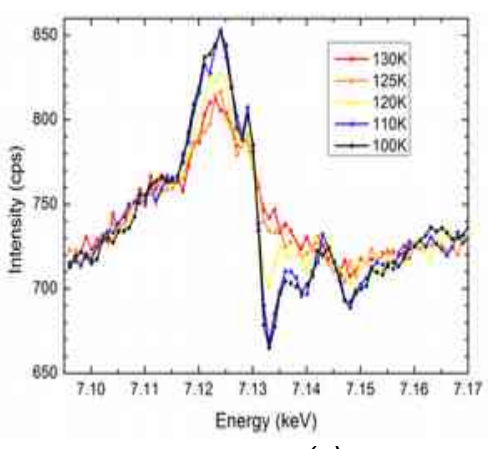

(c)

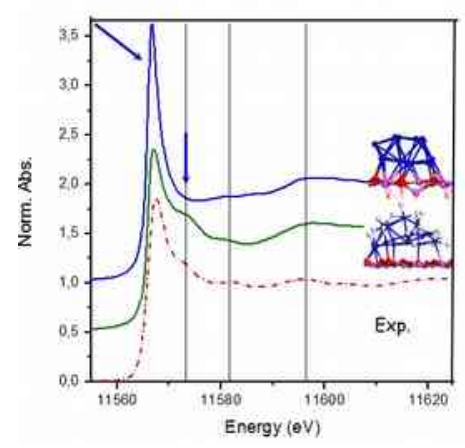

(d)

(a) Emergence of ferromagnetism in Cr doped LaMnO3 by XANES and XMCD; (b) Pressure induced insulator to metal transition in LaMnO3 from XANES in the pre-edge range ; (c) Charge order in $7 \mathrm{~nm}$ Fe3O4 film by SREXS, (d) Platinum-sub nanoparticle catalysts by HERDF XANES.

We present some studies carried out in our group, with focus on XAS study in perovskite oxides and recent results of HERDF-XANES and SXRS in ultrathin magnetite films and Pt nanoclusters. 


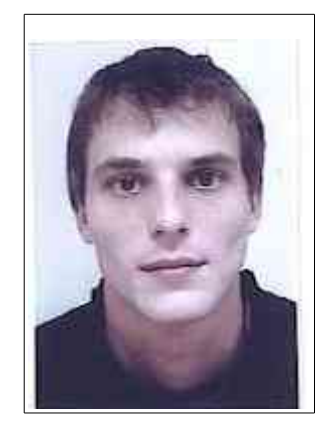

\title{
Nano-X: a Toulouse based platform dedicated to materials characterization using $X$-ray scattering techniques
}

\author{
N. Ratel-Ramond (1), L. Vendier (2), G. Viau (3), B. Malard (4) \\ (1) CEMES-CNRS, Toulouse, France, nicolas.ratel-ramond@cemes.fr \\ (2) LCC, CNRS Toulouse, France, laure.vendier@lcc-toulouse.fr \\ (3) LPCNO, INSA Toulouse, France, gviau@insa-toulouse.fr \\ (4) CIRIMAT, INPT ENSIACET, France, benoit.malard@ensiacet.fr
}

Corresponding author : nicolas.ratel-ramond@cemes.fr

Keywords : X-RAY DIFFRACTION, X-RAY SCATTERING, TECHNICAL PLATFORM

The nano-X platform is a tool dedicated to the characterization of nanomaterials using X-ray scattering and diffraction techniques. This project was initiated in 2013 and is supported by 4 laboratories based in Toulouse (CEMES, CIRIMAT, LCC and LPCNO). The nano-X platform is geographically based in the 4 constituting laboratories, who aim to maintain and develop $\mathrm{X}$-ray techniques at a competitive level.

The instrument pool is constituted of 6 equipment dedicated to X-ray diffraction and scattering techniques, including single crystal X-ray diffraction, powder diffraction, high resolution X-ray diffraction, Wide Angle X-ray scattering, microdiffraction and various sample environments for in-situ investigations. The equipment available allow the analysis of single crystal specimen, polycristalline bulk sample, thin films and multi layers, as well as powders or amorphous materials, under variable condition of temperature, pressure and atmosphere.

The main topics covered by the platform are stress and strain determination, texture measurements, crystal structure, quantitative analysis, sample crystallinity and nanomaterials.

The platform is accessible to physicists, chemists, materials scientists and industrial partners.

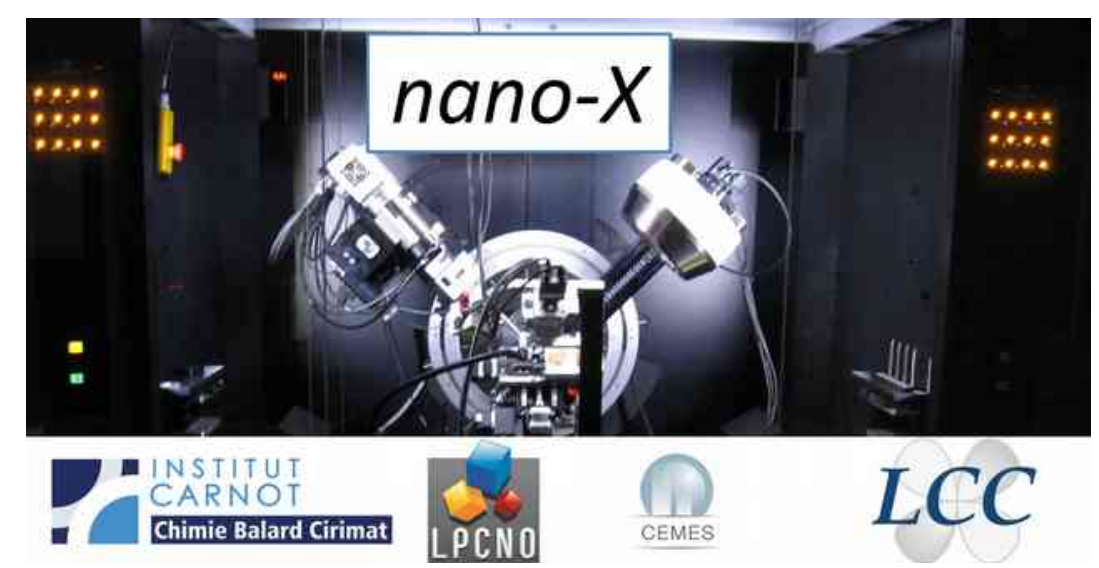




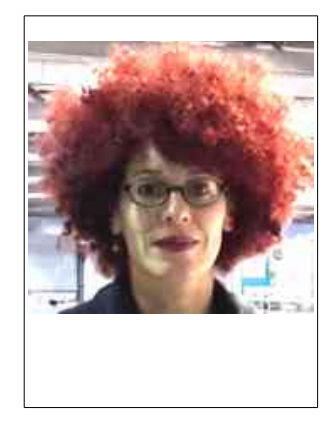

\title{
Laser activation of semiconductor nanostructures for ZnO nanorods based solar cells
}

\author{
Y. Rodríguez Martínez (1), J. A. Alba Cabañas (2), O. Cruzata (3), P. \\ Saint-Gregoire (4) and L. Vaillant Roca (1)
}

(1) Photovoltaic Research Laboratory, ENERMAT Division, Institute of Materials Science and Technology - Physics Faculty, University of Havana, Cuba, yerila@imre.uh.cu

(2) Physics Faculty - Photovoltaic Research Laboratory, ENERMAT Division, Institute of Materials Science and Technology, University of Havana, Cuba, jalba@estudiantes.fisica.uh.cu

(3) Laser Division, Institute of Materials Science and Technology, University of Havana, Cuba, osmel@imre.uh.cu

(4) MIPA Laboratory, Toulon and Nimes Universities, France, pstgregoire@gmail.com

\section{Corresponding author : vaillant@imre.uh.cu}

Keywords : ZnO NANORODS, INORGANIC NANOSTRUCTURED SOLAR CELLS, LASER ACTIVACION, SEEDING, CORE/SHELL STRUCTURES

Inorganic nanostructured solar cells can combine the stability of inorganic materials with the advantages of the $3^{\text {rd }}$ generation solar cells architecture. These devices are characterized by an extension of the main junction which is obtained through an incremental roughness of the materials, leading to the creation of embedded or inter penetrated junctions. Also, it is important to consider the possibility to exploit the effects of quantum confinement at the nanoscale like carrier multiplication, for achieving better conversion efficiencies. Although the conceptual design in this type of solar cells has a tremendous potential, there are huge experimental challenges to be overcome. Stability can be addressed by focusing in inorganic semiconductor materials, as mentioned before. In our case, we have chosen the $\mathrm{ZnO}$ nanorods network because of its friendly environmental impact and wide range of applications in solar cells.

For using a pulsed laser as a local heat source, we follow two different approaches. In the first one we applied the pulsed laser during the process for creating the nucleation points or seeds, before growing the $\mathrm{ZnO}$ nanorods by the hydrothermal technique. In the second one, we point out to the in-situ fabrication of semiconductor quantum dots on the $\mathrm{ZnO}$ nanorods surfaces, by pulsing the laser at different fluences and pulses number. The results are studied by Scanning electron microscopy (SEM) and Photoluminescence (PL).
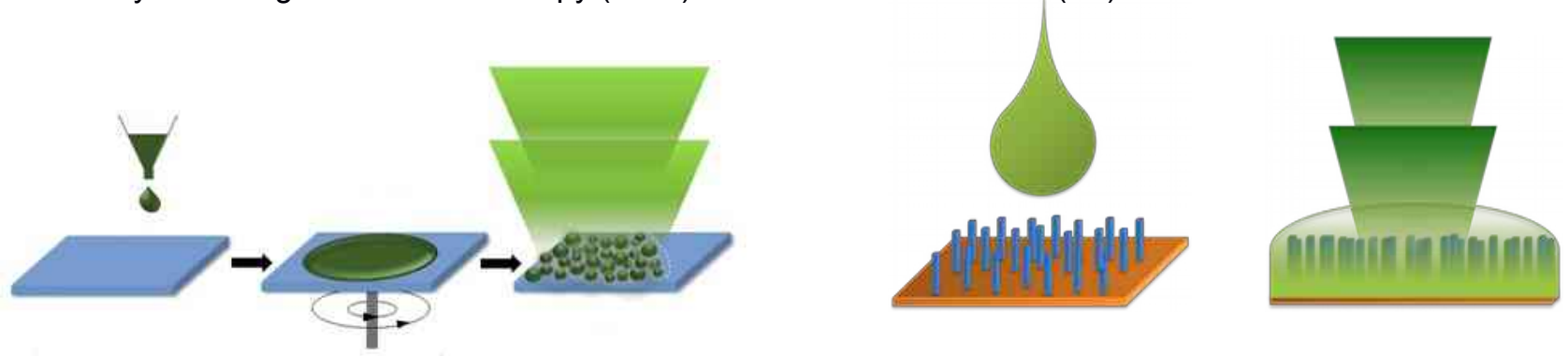

On the left, scheme of laser activation of the seeds for the $\mathrm{ZnO}$ nanorods. Right, in-situ laser induced growth of semiconductor quantum dots on the $\mathrm{ZnO}$ nanorods surfaces. 


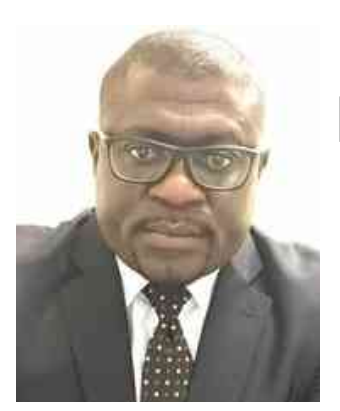

\title{
Dielectric permittivity enhancement and large electrocaloric effect in the lead free $\left(\mathrm{Ba}_{0.8} \mathrm{Ca}_{0.2}\right)_{1-x} \mathrm{La}_{2 \times / 3} \mathrm{TiO}_{3}$ ferroelectric ceramics
}

\author{
B. Asbani ${ }^{1,2}$, Y. Gagou ${ }^{1, a}$, M. Trček ${ }^{3}$, J.-L. Dellis ${ }^{1}$, M. Amjoud ${ }^{2}$, A. \\ Lahmar $^{1}$, D. Mezzane ${ }^{2}$, Z. Kutnjak ${ }^{3}$ and M. El Marssi ${ }^{1}$ \\ ${ }^{1}$ LPMC, Université de Picardie Jules Verne, 33 rue Saint-Leu, 80039 Amiens Cédex, France \\ ${ }^{2}$ LMCN, F.S.T.G. Université Cadi Ayyad, BP 549, Marrakech, Morocco \\ ${ }^{3}$ Jozef Stefan Institute, Jamova cesta 39, 1000 Ljubljana, Slovenia
}

Corresponding author : yaovi.gagou@u-picardie.fr

Keywords : FERROELECTRIC, ELECTROCALORIC, LANTHANUM, DIELECTRIC, RESPONSIVITY

Lanthanum (La) incorporation in the $\left(\mathrm{Ba}_{0.8} \mathrm{Ca}_{0.2}\right) \mathrm{TiO}_{3}(\mathrm{BCT})$ matrix induces enhancement of electrocaloric effect, decrease of Curie temperature and increase of dielectric permittivity. We studied the influence of La substitution on electrocaloric effect (ECE) in BCT matrix using both indirect and direct methods. From ferroelectric polarization and

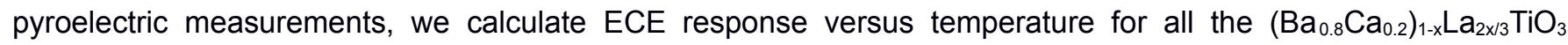
( $x B C T L$ ) ceramics compositions ranging from $x=0$ to 0.05 . The results showed good agreement between the two methods at the same applied electric field. A maximal value of electrocaloric temperature change $\Delta \mathrm{T}=0.30 \mathrm{~K}$ was obtained at $25 \mathrm{kV} / \mathrm{cm}$ corresponding to an $\mathrm{EC}$ responsivity $\xi=0.120 \times 10^{-6} \mathrm{~K} \mathrm{~m} / \mathrm{V}$, in a wide temperature region in the vicinity of the ferroelectric phase transition temperature $(250 \mathrm{~K}$ to $400 \mathrm{~K})$ for $\mathrm{x}=0.05$ that places this family as very promising materials for electrocaloric applications near room temperature.
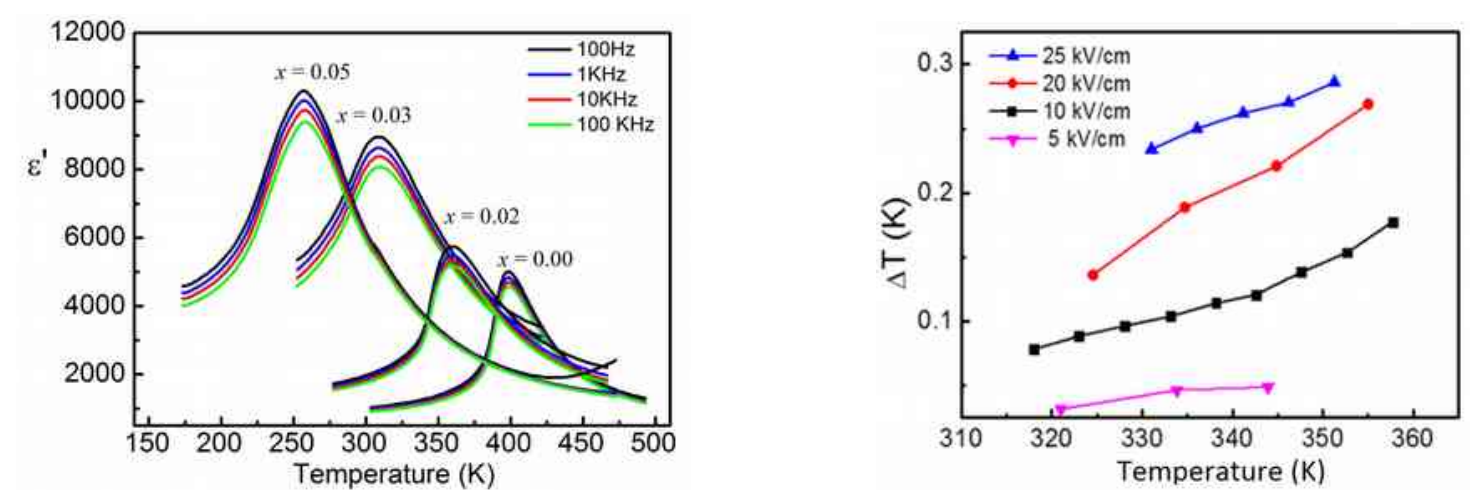

Dielectric enhancement (left) and electrocaloric temperature change (right) in BCLT 


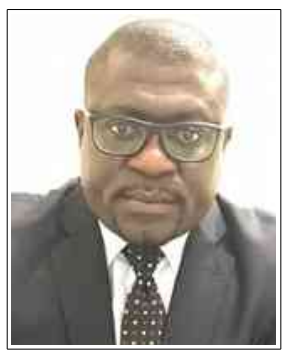

\title{
Multiferroic thin films and superlattices grown by PLD and their caracterisation using PPMS technique
}

\author{
Y. Gagou \\ LPMC, University of Picardie Jules Verne, 33 rue saint Leu, 80039 Amiens Cedex \\ Corresponding author : yaovi.gagou@u-picardie.fr
}

Keywords : MULTIFERROICS, PLD, PPMS TECHNIQUE, EPITAXIAL

Pulsed laser deposition (PLD) is one of the most efficient techniques to produce epitaxial thin films whose crystallographic orientation is well controlled during the growth process. This method is based on the bombardment of a dense ceramic target by a pulsed laser inside a pressure autoclave in which the substrate is prepared to receive the particles of material torn out during the interaction between the target and the laser.

In this work we show the experimental procedure of a thin film and a superlattice with optimal conditions of elaboration and the characterization by the means of new equipment available in our laboratory (a Lambda Physik $248 \mathrm{~nm}$ excimer laser in a MECA 2000 UHV chamber) to carry out this research theme. The materials studied are thin films of multiferroic oxides whose magnetic and transport properties are obtained by a Quantum Design's Physical Properties and Magnetic System (PPMS) equipment. The first results obtained on thin film and superlattice of Perovskite, TTB-type materials and Aurivillius phase doped by magnetic metal rare earths (Gd, Co, $\mathrm{Fe}, \mathrm{Mn} . .$.$) are discussed in view of the crystallographic aspects and magneto-electric properties.$

The epitaxial layers are grown on cubic single crystal (001)MgO and (001)STO substrates $\mathrm{a}_{\mathrm{mgo}}=4.213 \AA$ buffered with an oxide conducting layer of $\mathrm{La}_{1 / 2} \mathrm{Sr}_{1 / 2} \mathrm{CoO}_{3}$ (LSCO), $a_{L s c o}=3.805 \AA$. The tipical thickness is of about $4000 \AA$. The best conditions of syntheses are obtained by varying the deposition temperature (generally around $750{ }^{\circ} \mathrm{C}$ ) and the oxygen partial pressure (around $\sim 0.2 \mathrm{mbar}$ ). A deposition rate of $0.40 \AA /$ pulse was determined from $\mathrm{x}$-ray thickness and Laue oscillations observed on very thin films of materials. The surface quality of the layers are monitored using reflection high-energy electron diffraction (RHEED). XRD patterns were recorded using a D8 Discover diffractometer with Cu K-alpha radiation.
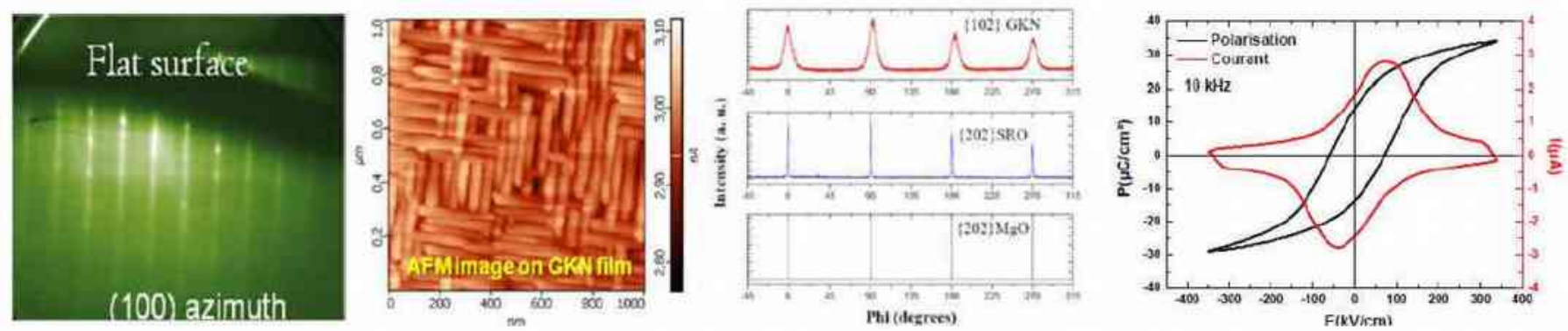

From the left to the right: RHEED, AFM image on GKN/STO, Epitaxy on PKN/MgO and FE properties of BT/MgO 


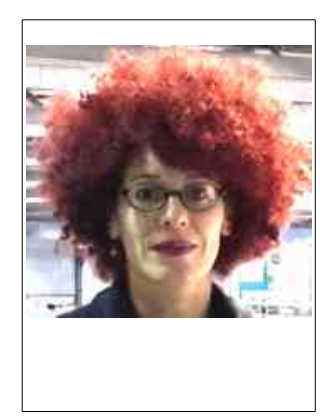

\title{
Energy confinement effects in CdTe nanocrystals embedded on ZnO nanorod matrix
}

\author{
S. Larramendi (1), L. Vaillant (2), P. Saint-Gregoire (3), \\ J. Ferraz Dias (4), and M. Behar (5)
}

(1) Institute of Materials Science and Technology (IMRE), University of Havana, Cuba,

(2) Institute of Materials Science and Technology (IMRE), University of Havana, Cuba, vaillant@fisica.uh.cu

(3) MIPA Laboratory, Universities of Toulon and Nimes, France, pstgregoire@gmail.com

(4) Ion Implantation Laboratory, Institute of Physics, Federal University of Rio Grande do Sul, Brazil, jfdias@if.ufrgs.br

(5) Ion Implantation Laboratory, Institute of Physics, Federal University of Rio Grande do Sul, Brazil, behar@if.ufrgs.br

\section{Corresponding author: saull@fisica.uh.cu}

Keywords : LOW DIMENSIONAL STRUCTURES; HYDROTHERMAL CRYSTAL GROWTH , PHYSICAL VAPOR DEPOSITION PROCESSES, ZINC COMPOUNDS, SEMICONDUCTING II-V, SOLAR CELLS

A ZnO nanorod structure was grown by the hydrothermal method and interpenetrated with CdTe using the isothermal closed space sublimation technique [1]. The obtained structure was studied by using the Rutherford backscattering spectrometry (RBS), Scanning Electron Microscopy (SEM), and High Resolution Transmission Electron Microscopy (HRTEM). The X-ray Diffraction (XRD) technique confirmed the presence of CdTe nanocrystals (NCs) of very small size formed on the surface and in the interspaces between the ZnO nanorods. The RBS observations together with the SEM observations give information on the obtained structure. Finally the photoluminescence studies show evidence of energy confinement effect in the grown CdTe NCs. The obtained structure of vertically-aligned $\mathrm{ZnO}$ nanorods interpenetrated with CdTe NCs has some similarity with those structures proposed for excitonic organic solar cells. Therefore we propose that the present $\mathrm{CdTe} / \mathrm{ZnO}$ heterostructure can be a good candidate for an efficient solar cell device.
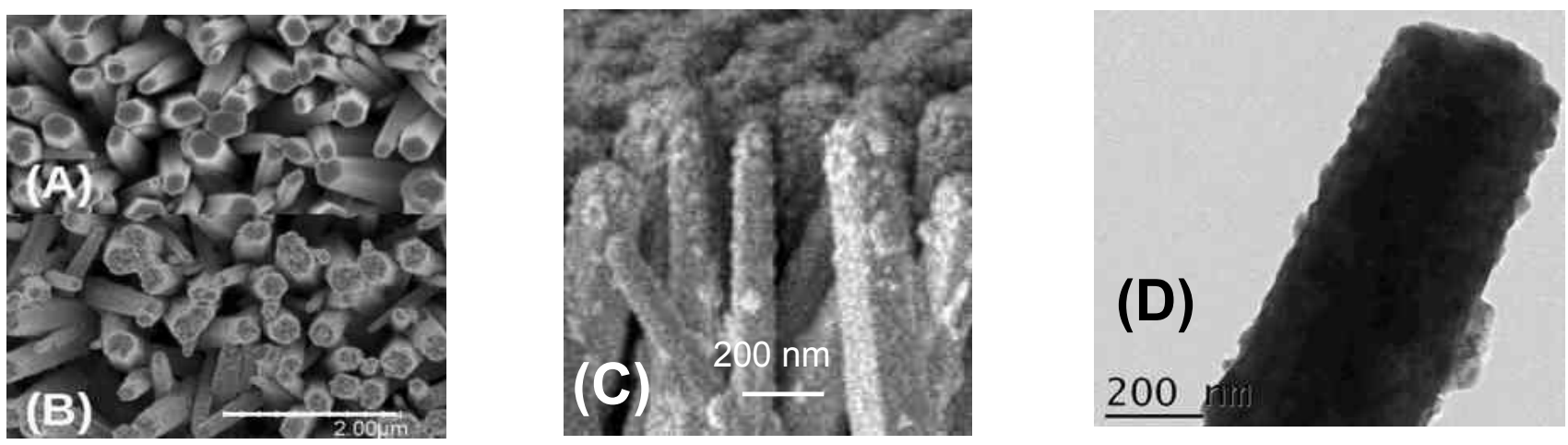

Nanocrystals of CdTe over ZnO nanorods superficies grown by isothermal closed space sublimation
(A) $\mathrm{ZnO}$ nanorods network prior to deposition, (B) ZnO nanorods network after deposition (SEM images)
(C) ZnO nanorods with deposited CdTe-NCs (SEM image)
(D) A TEM image of an object similar to that shown in (C)

[1] S. Larramendi, Lidice Vaillant Roca, Pierre Saint-Grégoire, Johnny Ferraz Dias, Moni Behar, Infiltration of CdTe nanocrystals into a $\mathrm{ZnO}$ wire vertical matrix by using the isothermal closed space technique, Journal of Crystal Growth, $\underline{475}, 274(2017)$ 


\title{
Theoretical study of the performance of homo and heterojunctions based on $\mathrm{CuInSe}_{2}$
}

\author{
E.M. Keita , B. Mbow, C. Sene, M.S. Mane
}

Laboratoire des Semiconducteurs et d'Energie Solaire, Département de Physique, Faculté des Sciences et Techniques, Université Cheikh Anta Diop, Dakar, Sénégal

Email address : elouazy@hotmail.fr

Keywords : $\quad$ THIN FILMS, CulnSe 2 , CulnS 2 , INTERNAL QUANTUM EFFICIENCY, HOMO AND HETEROJUNCTIONS

The objective of this work is to predict and enhance the electrical performance of CulnSe ${ }_{2}$ photovoltaic devices by optimizing geometrical and electrical parameters. For this purpose, Two, three and four-layer structures (including window layer and substrate) are modeled for the theoretical determination of the internal quantum efficiency and the short-circuit photocurrent. First we studied Homojunctions based on CulnSe $e_{2}$ considering the following models: homojunction (CulnSe $2(p) / \mathrm{CulnSe}_{2}(\mathrm{n})$ ), homojunction deposited on substrate $\left(\mathrm{CuInSe}_{2}(\mathrm{p}) / \mathrm{CulnSe} \mathrm{C}_{2}(\mathrm{n}) / \mathrm{CulnSe}_{2}\left(\mathrm{n}^{+}\right)\right.$), homojunction with window layer $\left(\mathrm{CulnS}_{2}\left(\mathrm{p}^{+}\right) / \mathrm{CulnSe}_{2}(\mathrm{p}) / \mathrm{CulnSe} \mathrm{e}_{2}(\mathrm{n})\right)$, homojunction with window layer deposited on substrate $\left(\mathrm{CulnS}_{2}\left(\mathrm{p}^{+}\right) / \mathrm{CulnSe}_{2}(\mathrm{p}) / \mathrm{CulnSe}_{2}(\mathrm{n}) / \mathrm{CulnSe}_{2}\left(\mathrm{n}^{+}\right)\right)$. The effects of the window layer and the substrate are highlighted. Secondly we considered Heterojunctions based on CulnSe $e_{2}$ using wide gap windows layers based on $\mathrm{ZnO}$ and CdS according to the following models : $\mathrm{ZnO}\left(\mathrm{n}^{+}\right) / \mathrm{CdS}(\mathrm{n}) / \mathrm{CulnS}_{2}(\mathrm{p}) / \mathrm{CulnSe}_{2}\left(\mathrm{p}^{+}\right)$and $\mathrm{ZnO}\left(\mathrm{n}^{+}\right) / \mathrm{CdS}(\mathrm{n}) /$ $\mathrm{CulnSe}_{2}(\mathrm{p}) / \mathrm{CulnS}_{2}\left(\mathrm{p}^{+}\right)$.

Based on the continuity equation which governs transport of carriers in semiconductor material, models of calculation of spectral responses of homo and heterojunctions based on CulnSe ${ }_{2}$ are proposed. For each structure we have presented the energy band diagram based on the Anderson model [1] and the associated continuity equation. We have established the corresponding boundary conditions between the different layers and determined the expression of the photocurrent. This expression depends on the geometrical, electrical and optical parameters that characterize the photovoltaic cell.

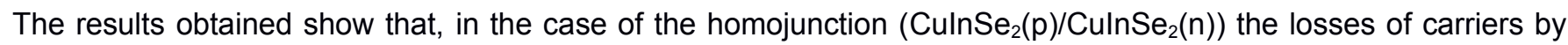
recombination at the surface of the front layer reduce the influence of the diffusion length and provoke a low internal quantum efficiency. The deposition of a window layer based on CulnS $\mathrm{S}_{2}$ on the front face (illuminated face) allows to reduce carrier losses at the surface and enhances the spectral response for radiation energies lower than his energy band gap $(1.04<\mathrm{E}<1.57 \mathrm{eV})$. The substrate allows to enhance the internal quantum efficiency in the range of low energies $(1.04<\mathrm{E}<1.4 \mathrm{eV})$. The structure $\mathrm{CulnS}_{2}\left(\mathrm{p}^{+}\right) / \mathrm{CulnSe}_{2}(\mathrm{p}) / \mathrm{CulnSe} \mathrm{C}_{2}(\mathrm{n}) / \mathrm{CulnSe}_{2}\left(\mathrm{n}^{+}\right)$gives the best theoretical spectral response in the case of the homojunctions. The spectral response curves show that a thin thickness of the window layer (less than $0.1 \mu \mathrm{m}$ ) is sufficient.

For the heterojunction $\mathrm{ZnO}\left(\mathrm{n}^{+}\right) / \mathrm{CdS}(\mathrm{n}) / \mathrm{CulnS}_{2}(\mathrm{p}) / \mathrm{CulnSe}_{2}\left(\mathrm{p}^{+}\right)$where the materials are arranged with decreasing gap, the internal quantum efficiency shows that a thin thickness of the base is sufficient (on the order of 0.1 to 0.3 $\mu \mathrm{m}$ ) when the recombination velocity at the interface base-substrate is lower than $2 \times 10^{5} \mathrm{~cm} \cdot \mathrm{s}^{-1}$. For high recombination velocity at the interface base-substrate (greater than $2 \times 10^{6} \mathrm{~cm} . \mathrm{s}^{-1}$ ) it is preferable to increase the thickness of the base to a value greater than $3 \mu \mathrm{m}$.

For the structure $\mathrm{ZnO}\left(\mathrm{n}^{+}\right) / \mathrm{CdS}(\mathrm{n}) / \mathrm{CulnSe}_{2}(\mathrm{p}) / \mathrm{CulnS}_{2}\left(\mathrm{p}^{+}\right)$the spectral response curves obtained are more elevated in comparison with the previous model. The recombination velocity at the interface base-substrate becomes less influential on the internal quantum efficiency. The spectral response is due to the absorption of the base and the space charge region. A base thickness greater than or equal to $3 \mu \mathrm{m}$ is better.

Calculation of the theoretical short-circuit photocurrent under the solar spectra (AM 0, AM 1 and AM 1.5) was established for each structure using numerical integration method. We have also determined the saturation current using some essential notions of semiconductor physics. An approximate resolution methods (graphic and numerical) are used to determine the short-circuit current, the open circuit voltage, the maximum power point and allow to evaluate the efficiency of the photovoltaic cell. These results have been applied to the heterojunction models. The calculated values remain in the range of the values reported in the literature [2]. Our results validate the different models established to model the physical phenomena studied. This study is very important to dimension and optimize the different photoconductive layers.

[1] R. L. Anderson, "Germanium- gallium arsenide heterojunctions", IBM J.Res.Dev.4, 283, 1960.

[2] Subba Ramaiah Kodigala, "Cu( $\left(\ln _{1-x} \mathrm{Ga}_{x}\right) \mathrm{se}_{2}$ based thin solar cells", 2010, Volume 35, Academic Press, ELSEVIER.Inc, p. 16. 